\title{
Small-Scale Diagenetic Heterogeneity Effects on Reservoir Quality of Deep Sandstones: A Case Study from the Lower Jurassic Ahe Formation, Eastern Kuqa Depression
}

\author{
LiKuan Zhang $\mathbb{D}^{1}{ }^{1}$ Xiaorong Luo, ${ }^{1,2}$ Mingze Ye $\mathbb{D}^{1,2}$ Baoshou Zhang, ${ }^{3}$ Hongxing Wei, ${ }^{3}$ \\ Binfeng Cao $\left({ }^{1},{ }^{1}\right.$ Xiaotong Xu $\left(\mathbb{1},{ }^{4}\right.$ Zhida Liu, ${ }^{5}$ Yuhong Lei, ${ }^{1}$ and Chao Li ${ }^{1}{ }^{1}$ \\ ${ }^{1}$ Key Laboratory of Petroleum Resources Research, Institute of Geology and Geophysics, Chinese Academy of Sciences, Beijing, China \\ ${ }^{2}$ University of Chinese Academy of Sciences, Beijing, China \\ ${ }^{3}$ Research Institute of Exploration and Development, Tarim Oil Field Company, PetroChina, Korla, China \\ ${ }^{4}$ School of Geosciences, China University of Petroleum, Qingdao, China \\ ${ }^{5}$ School of Earth Sciences, Northeast Petroleum University, Daqing, China
}

Correspondence should be addressed to LiKuan Zhang; zhanglikuan@mail.iggcas.ac.cn

Received 29 October 2020; Revised 20 January 2021; Accepted 6 March 2021; Published 24 March 2021

Academic Editor: Peter Leary

Copyright (C) 2021 LiKuan Zhang et al. This is an open access article distributed under the Creative Commons Attribution License, which permits unrestricted use, distribution, and reproduction in any medium, provided the original work is properly cited.

The Lower Jurassic Ahe Formation is an important exploration target for deep clastic reservoirs in the eastern Kuqa Depression. The Ahe Formation sandstones show heterogeneous porosity and permeability petrophysical properties. These properties have been poorly understood, limiting forecast of petroleum accumulations and making it difficult to develop the reservoirs. Based on cores, thin sections, SEM, and fluid inclusions, this study examined sandstone composition and texture and diagenetic heterogeneity at the core scale. The aim was to understand the influence of variations in detrital composition and texture on diagenetic and reservoir quality evolution. The Ahe Formation sandstones are dominantly fine- to coarse-grained litharenites, with minor feldspathic litharenites. In fining-up sand beds, detrital grain size determines the degree of mechanical compaction and, consequently, the abundance of porosity through ductile grains and muddy matrix. Local complete calcite cementation is a noticeable exception to this general trend. Three sandstone petrofacies have been defined based on texture and framework composition, detrital matrix, diagenesis, and pore types: (1) ductile-lean sandstone, (2) ductile-rich sandstone, and (3) tightly calcite-cemented sandstone. Different petrofacies experienced contrasting diagenetic and porosity evolution pathways. Ductilelean sandstones underwent lower degree of compaction relative to ductile-rich sandstones during the eodiagenesis stage, and extensive grain dissolution occurred. The petrofacies remained relatively porous and permeable before early oil arrival. With continued burial, the porosity and permeability in the sandstones were further reduced by cementation. The petrofacies still had moderate porosity and permeability and were substantially charged when late petroleum migrated into the reservoirs. Thus, ductile-lean sandstones constitute effective reservoir rocks in deep reservoirs. By translating petrofacies to signatures of well logs, the effective properties of the reservoir rocks can be forecasted at the well scale.

\section{Introduction}

The exploration and development of deep clastic reservoirs have obtained more attention in China. Up to now, there are three most important provinces of deep clastic reservoirs: Kuqa Depression in Tarim Basin, Sichuan Basin, and central Junggar Basin [1]. Most deep sandstones experienced multistage tectonic/burial processes and fluid-rock interactions, and the original pore structure in the sandstones was extensively modified during burial. They have overall ultralow porosity and permeability and small pore throat $[2,3]$.

However, numerous studies indicated that deep reservoirs have strongly heterogeneous porosity and permeability petrophysical properties. Consequently, reservoir rocks with good porosity, permeability, and oil/gas shows are locally common in the heterogeneous reservoirs [4-6]. The 


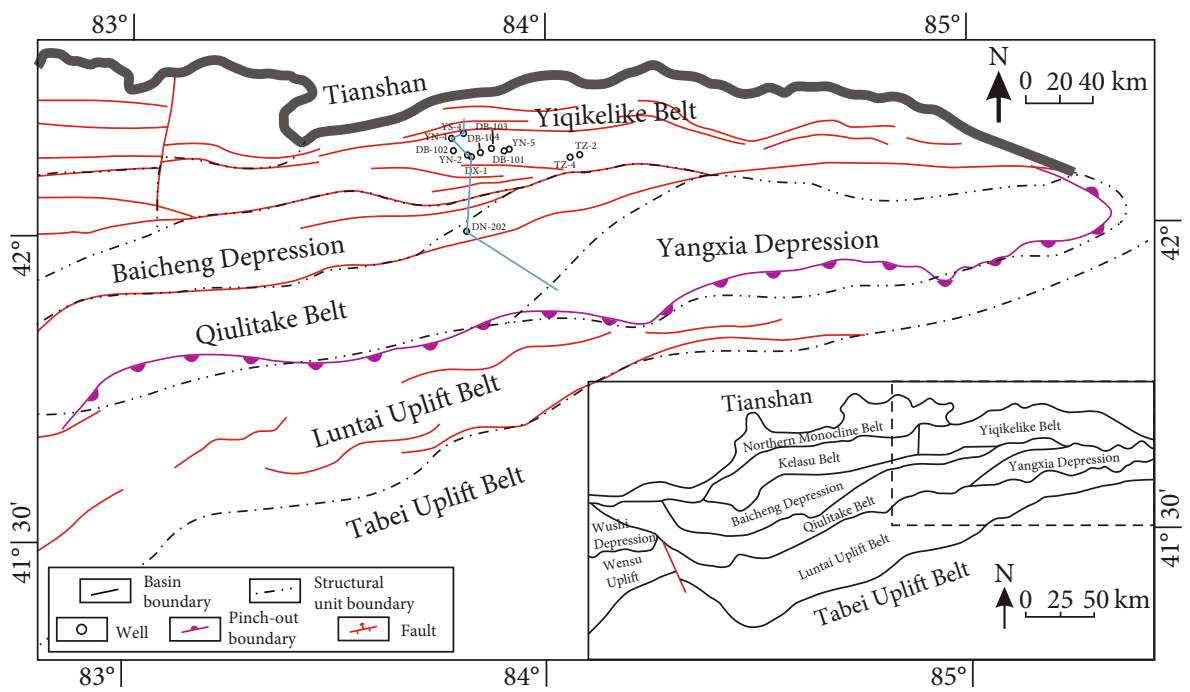

(a)

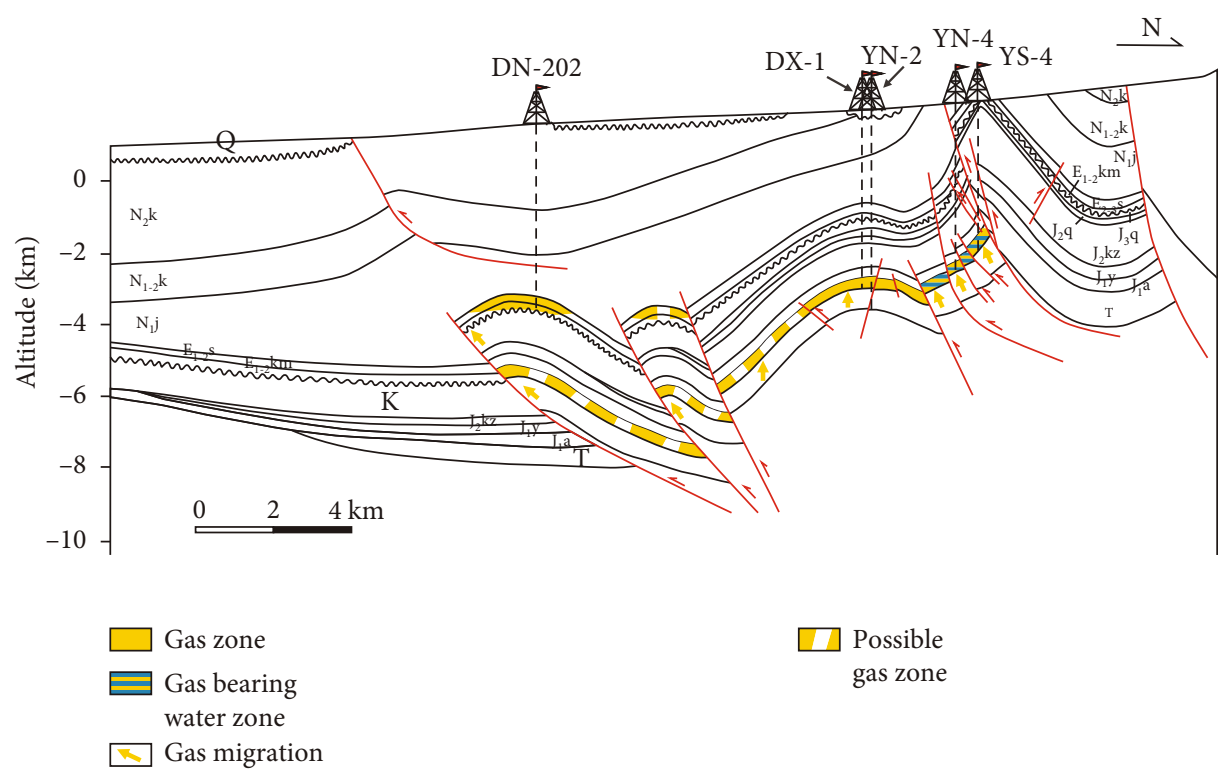

(b)

Figure 1: (a) Regional geological map showing structural features of the eastern Kuqa Depression and location of the study area [14]. (b) Typical reservoir profile.

formation and distribution of the effective reservoir rocks are one of the most important issues for exploration of deep clastic reservoirs and are of great significance for the forecasting of deep petroleum accumulations [7, 8].

Heterogeneity in petrophysical properties of deeply buried petroleum reservoirs is the result of original depositional conditions, postdepositional diagenesis, and tectonic activities. Sandstone composition and texture and original porosity and permeability determine the extent and distribution of eodiagenesis $\left(0-2 \mathrm{~km}\right.$ depth and $\left.>70^{\circ} \mathrm{C}\right)$, which in turn exert a substantial control on burial diagenesis $(>2 \mathrm{~km}$ depth and $>70^{\circ} \mathrm{C}$ ) [9-11]. Variations in detrital composition and texture can cause strikingly different diagenetic types and contents, contrasting processes within a single intrachannel sand unit [12], and differential porosity reduction rate in different locations.
Thus, a heterogeneous reservoir consists of permeable rocks generally separated by low-permeability/impermeable rocks: e.g., fine-grained, ductile grain-rich sandstones and completely calcite-cemented sandstone zones. These lowpermeability/impermeable rocks are arranged at different scale lengths $[7,8]$. In such a heterogeneous reservoir, petroleum migration and accumulation are extremely uneven, markedly different from those in a homogenous reservoir $[8,13]$. Therefore, it is essential to understand the influence of sandstone composition and texture on variations in diagenetic types and processes. This can aid in understanding heterogeneous reservoir evolution and petroleum flow during deep burial, revealing the origin and distribution of effective porosity and permeability in such sandstone reservoirs.

Many wells have been drilled in the Dibei area of the eastern Kuqa Depression since 1998 (Figure 1(a)), and significant 


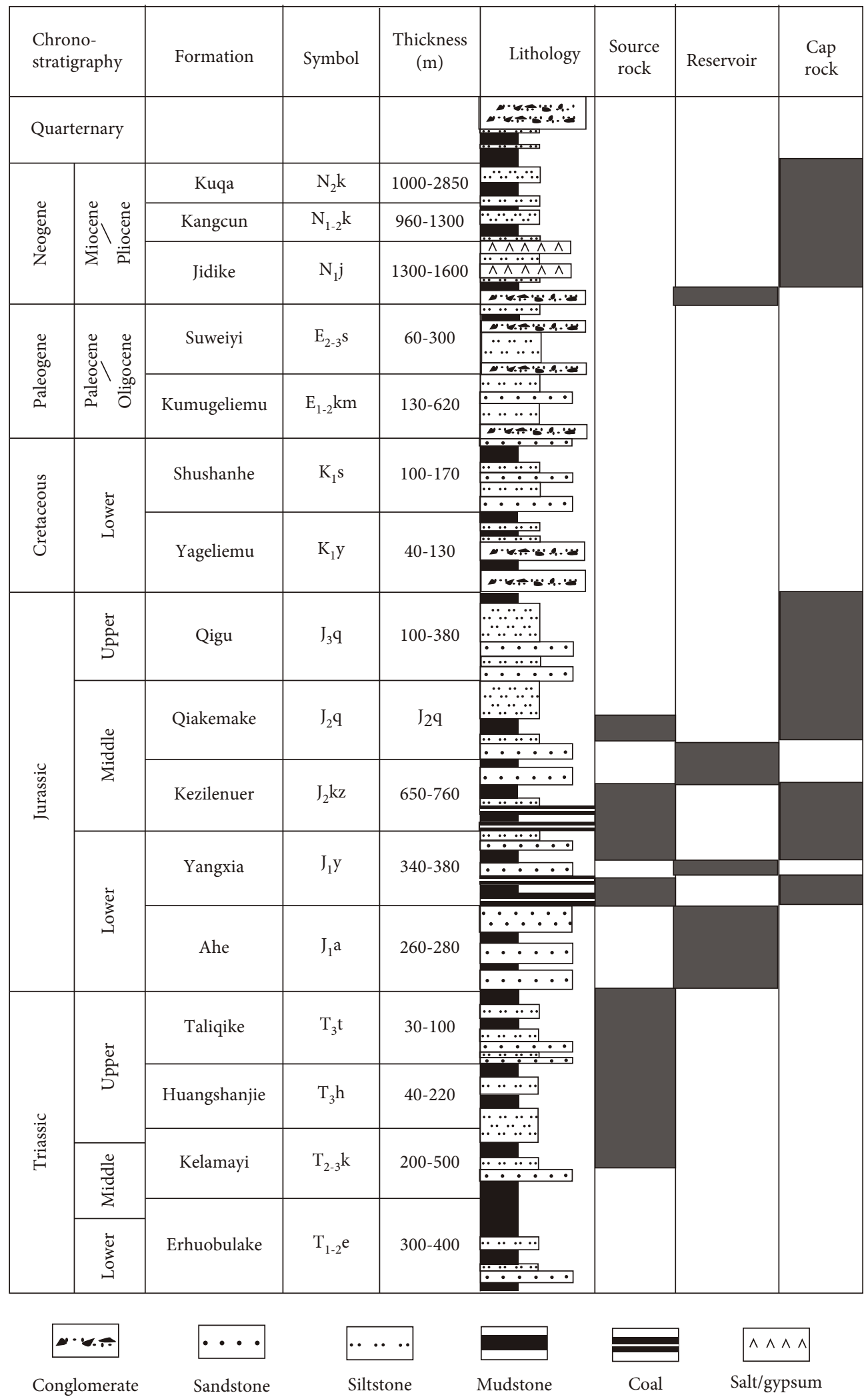

FIgUre 2: Generalized stratigraphic column of the eastern Kuqa Depression [24].

petroleum discoveries were obtained in the Lower Jurassic Ahe Formation. The natural gas reserves were estimated to be approximately 56.8 billion cubic meters and condensate oil reserves estimated to be about 2.6 million tons, showing good prospect for deep exploration. In the Dibei area, the Ahe Formation has burial depths of generally more than 
$\mathrm{YN}-2$

DB-102
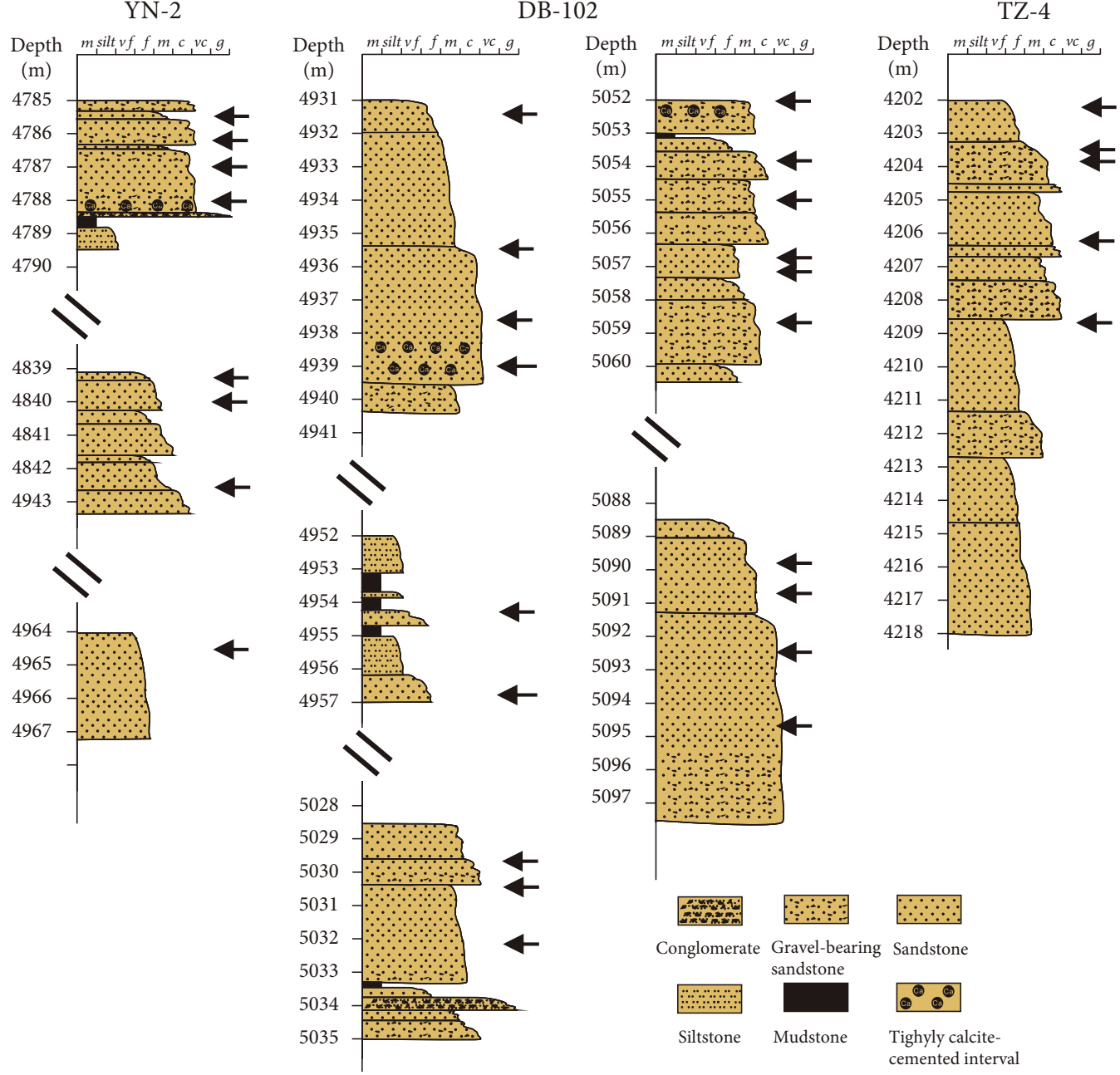

Figure 3: Depositional lithology of drill cores and sampling positions.

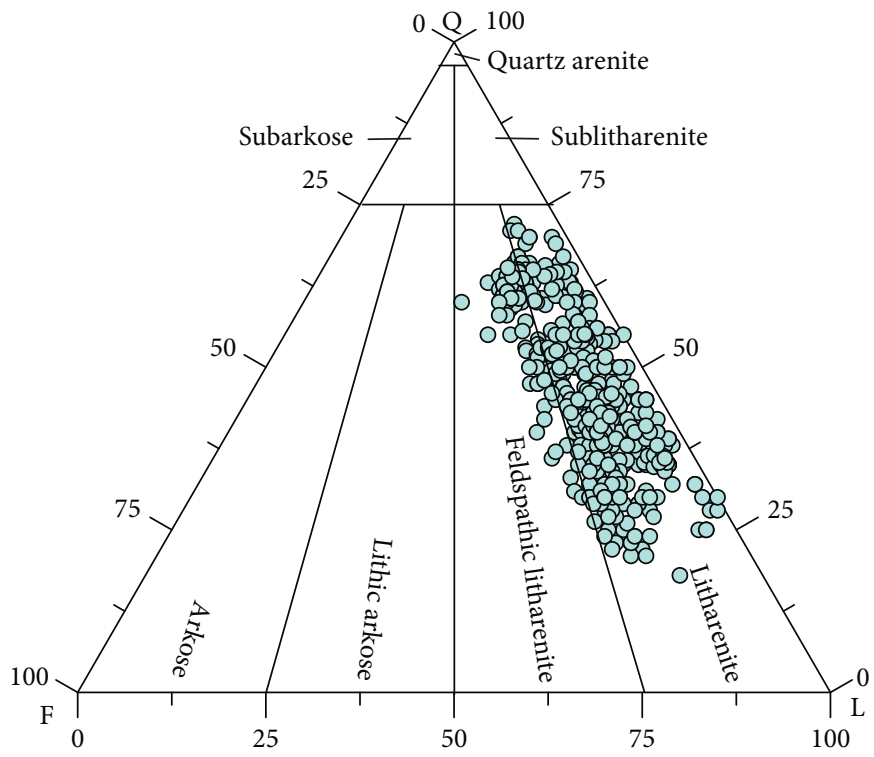

(a)

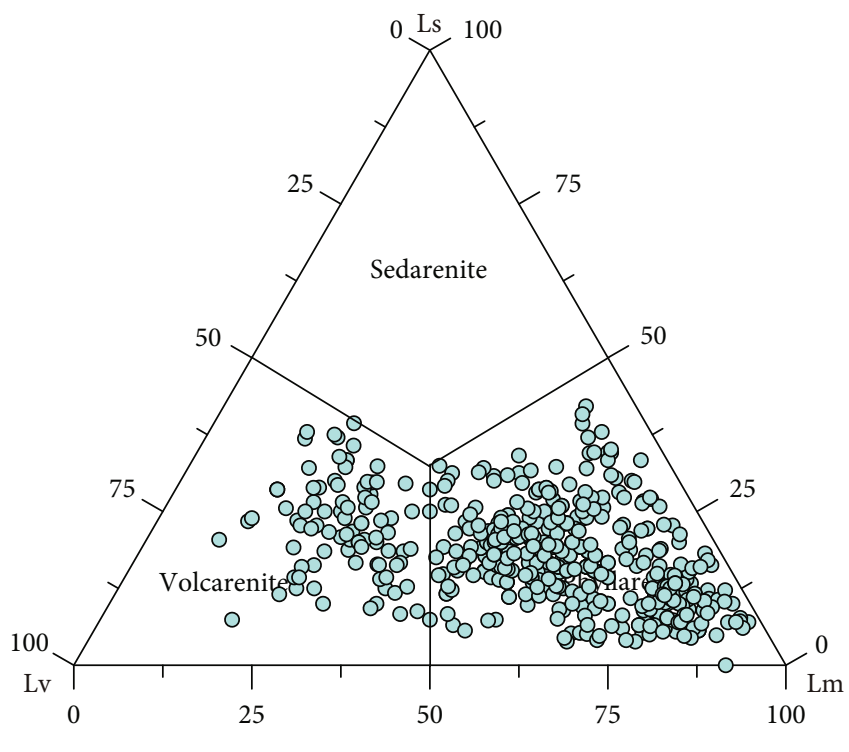

(b)

Figure 4: Sandstone Q-F-L triangular classification of the Ahe Formation using the classification of Folk [27]. 


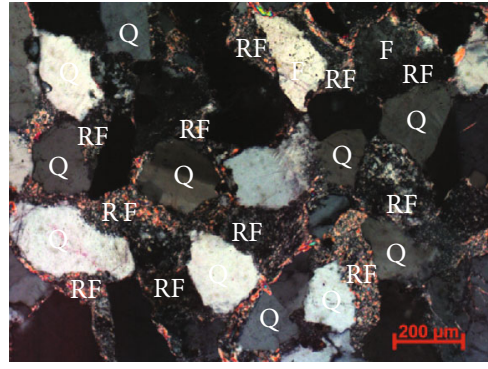

(a)

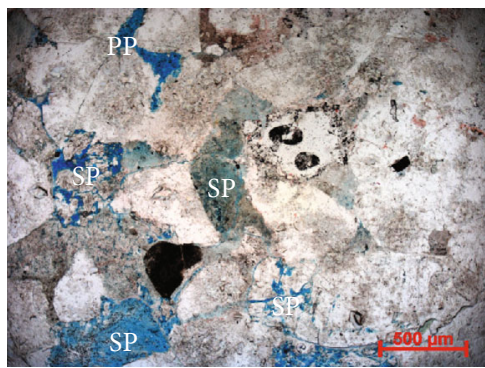

(c)

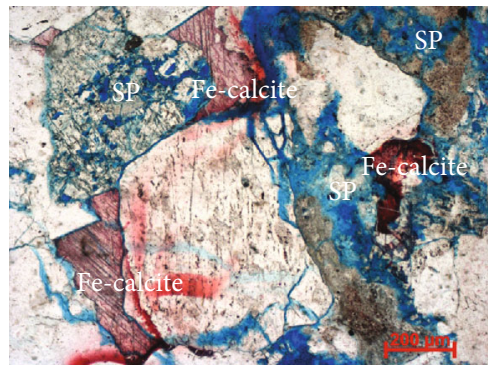

(e)

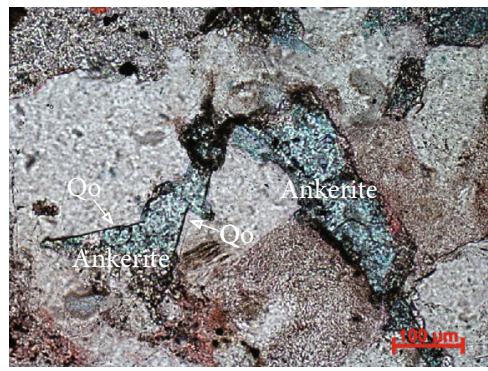

(g)

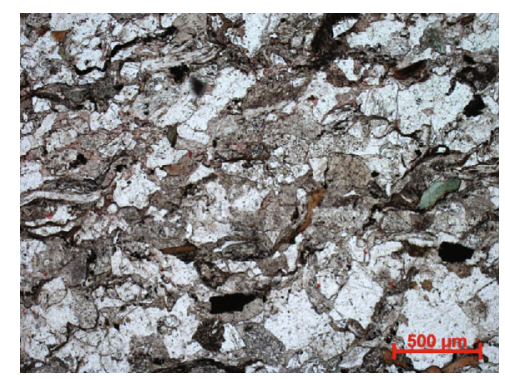

(b)

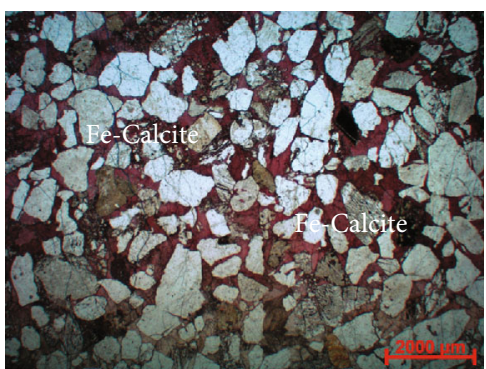

(d)

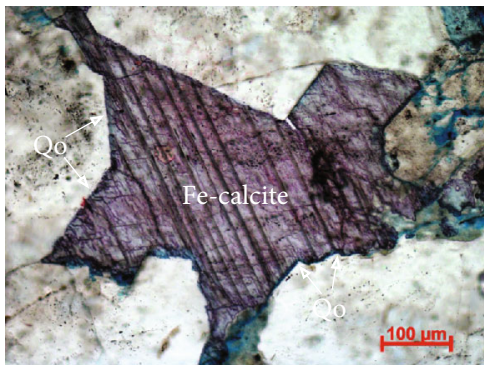

(f)

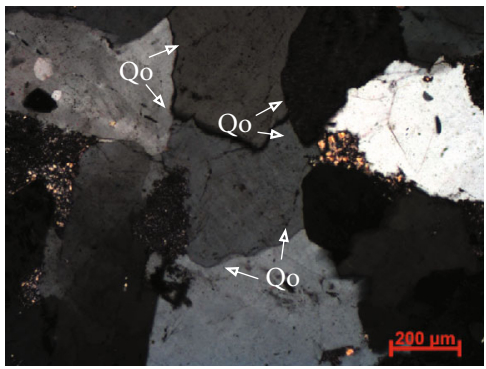

(h)

FIGURE 5: Thin section images of sandstones (pore space is highlighted in blue). (a) Sample $5147.5 \mathrm{~m}$, well DB-102, cross-polarized light (XPL): rock fragments subjected to compaction, being squeezed into intergranular pore throats and blocking pores. (b) Sample 4202.1 m, well TZ-4, plane-polarized light (PPL): finer-grained sandstones in which framework grains are strongly compacted with few pores. (c) Sample $4203.5 \mathrm{~m}$, well TZ4, PPL: coarser-grained sandstones in which grains are compacted with a few primary pores and secondary dissolution pores. (d) Sample 4937.7 m, well DB-102, PPL: tightly calcite-cemented sandstones; grains show a floating appearance, and compaction is weak. (e) Sample $4206.1 \mathrm{~m}$, well TZ-4, PPL: patchy calcite filling primary pores and dissolution pores, indicating it formed after dissolution. (f) Sample $4787 \mathrm{~m}$, well YN-2, PPL: patchy calcite precipitating after or is synchronous with quartz overgrowths. (g) Sample $4842.6 \mathrm{~m}$, well YN-2, PPL: ankerite formed after quartz overgrowths. (h) Sample $4203.9 \mathrm{~m}$, well TZ-4, XPL: local intergranular pressure dissolution and quartz overgrowths. Framework grains: quartz (Q), feldspar (F), and rock fragment (RF); cement: quartz overgrowth (Qo); primary porosity (PP) and secondary porosity (SP).

$4500 \mathrm{~m}$. The sandstones have porosities ranging from $0.3 \%$ to $12.2 \%$ and permeabilities ranging between 0.01 and $2670 \mathrm{mD}$. However, in the heterogeneous reservoirs, the formation and distribution of effective reservoir rocks have been poorly understood, limiting forecast of petroleum accumulations and making it difficult to develop the area. With an integrated method of thin section petrography, SEM, and fluid inclusion analysis, the study seeks to address the following problems: 


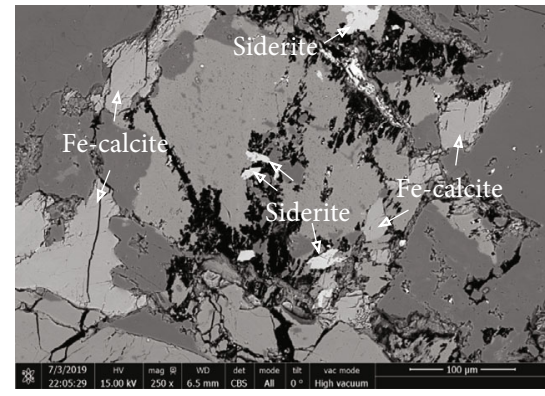

(a)

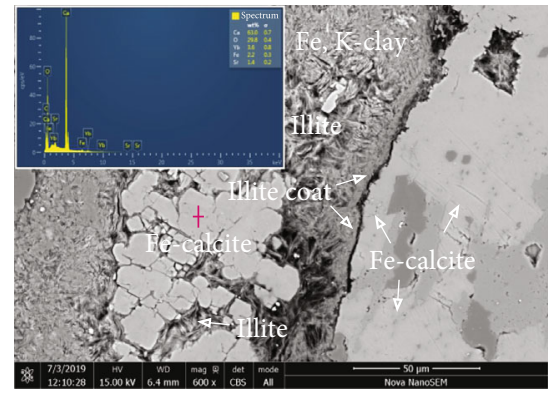

(c)

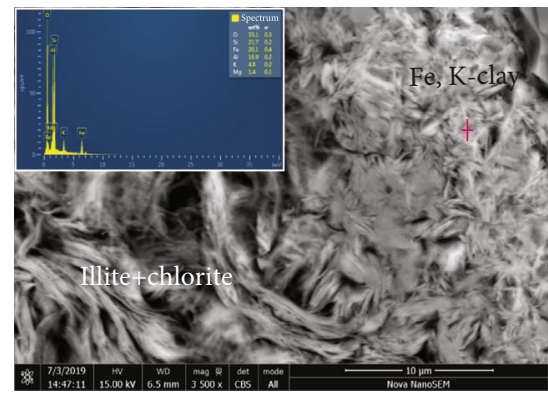

(e)

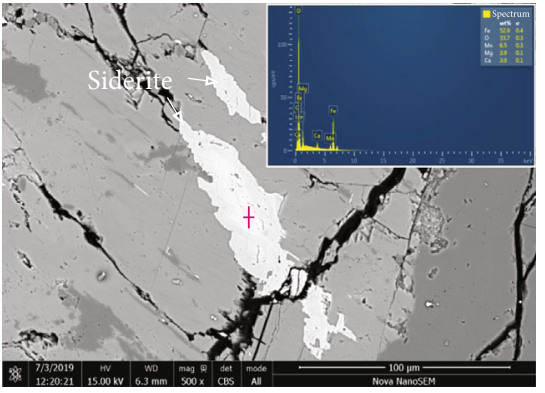

(b)

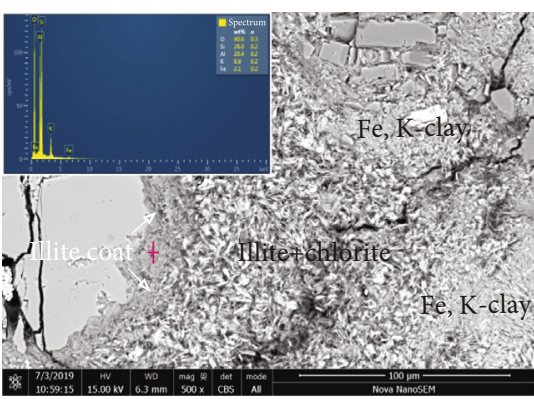

(d)

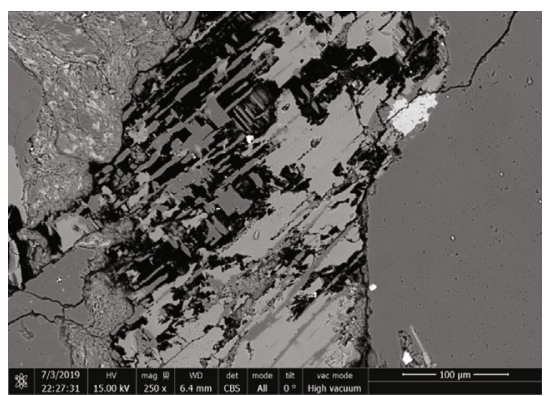

(f)

Figure 6: BSE images of sandstones. (a) Sample $4206.1 \mathrm{~m}$, well TZ-4: calcite and siderite filling intergranular pores and feldspar dissolution pores. (b) Sample $5034.7 \mathrm{~m}$, well DB-102: siderite filling feldspar dissolution pores. (c) Sample $5034.7 \mathrm{~m}$, well DB102: grain-coating and porefilling illite and Fe-calcite filling feldspar dissolution pores and engulfing illite. (d) Sample $5034.7 \mathrm{~m}$, well DB-102: grain-coating illite and pore-filling illite and chlorite. (e) Sample $4785.5 \mathrm{~m}$, well YN-2: illite and chlorite. (f) Sample $4206.1 \mathrm{~m}$, well TZ-4: feldspar dissolution.

(1) To classify sandstone petrofacies and to examine petrographic and petrophysical characteristic of different petrofacies

(2) To indicate whether different petrofacies have undertaken different diagenetic pathways

(3) Understand the formation of effective porosity and permeability in the heterogeneous deep reservoirs

\section{Geological Setting}

The Kuqa Depression is located in the northern part of the Tarim Basin, and it is confined by the Southern Tianshan Orogenic Belt to the north and by the Tabei Uplift Belt to the south. The depression extends about $550 \mathrm{~km}$ from east to west and $30-80 \mathrm{~km}$ from north to south with an area of approximately $30,000 \mathrm{~km}^{2}$ [14]. The depression is divided into seven units: Northern Monocline Belt, KelasuYiqikelike Belt, Qiulitake Belt, Luntai Uplift Belt, Wushi
Depression, Baicheng Depression, and Yangxia Depression $[14,15]$ (Figure 1(a)). The Dibei area, the focus of this study, lies in the Yiqikelike belt in the eastern Kuqa Depression.

The Kuqa Depression is a superimposed basin that was originally a foreland basin from the Late Permian to Triassic, then an extensional depression basin from the Jurassic to Paleogene, and finally a regenerated foreland basin from the Neogene to Quaternary [16]. The foreland basin was initiated by the thrusting of the Southern Tianshan Orogenic Belt since the Late Permian [17] and finished its final evolution until the Early Jurassic. When entering the Early Jurassic, the Tarim Basin experienced thermal cooling subsidence. At this point, the Kuqa Depression entered the intracontinental extensional depression stage. The uplift during the Late Cretaceous resulted in the loss of the Upper Cretaceous sediments. Subsequently, the Kuqa Depression subsided slowly during the Paleogene and subsided rapidly during the Miocene. Since the Pliocene, the depression was dominated by lateral horizontal compressional stress 


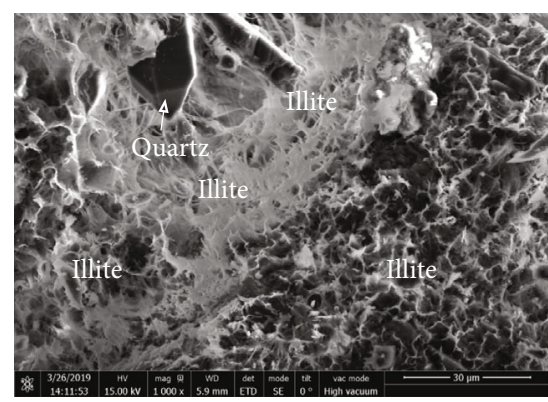

(a)

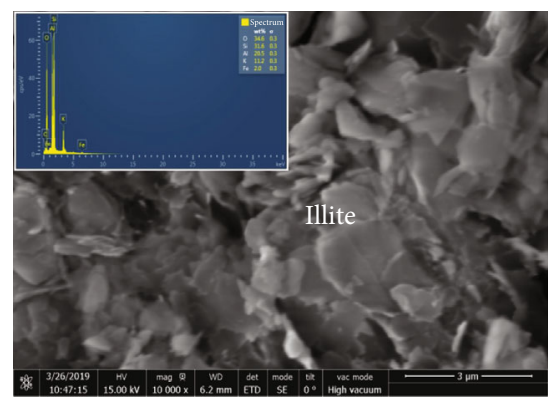

(c)

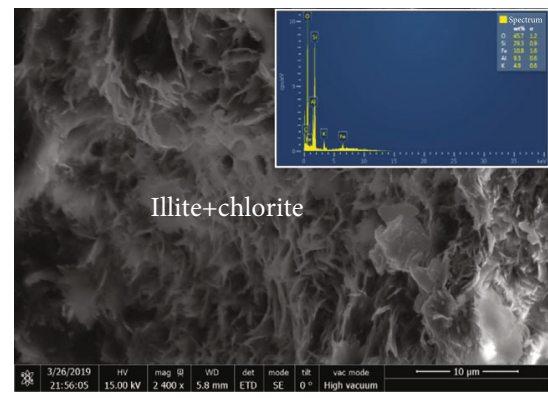

(e)

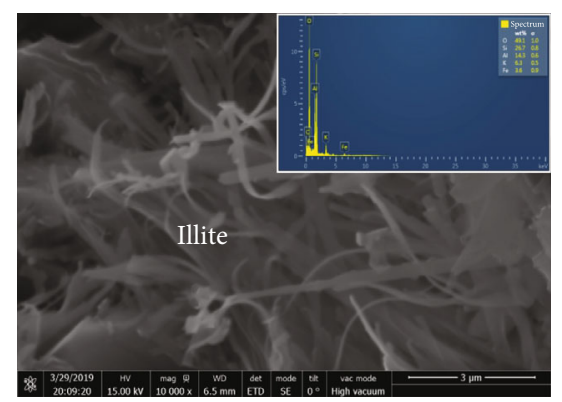

(b)

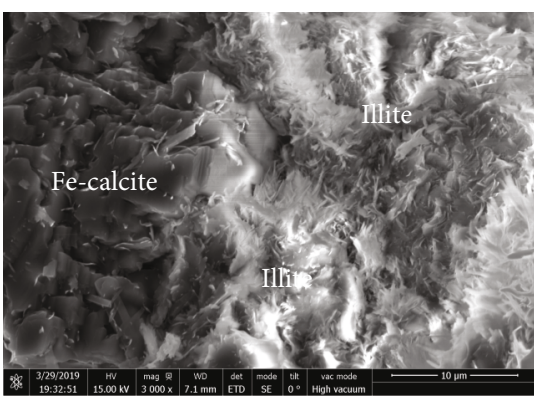

(d)

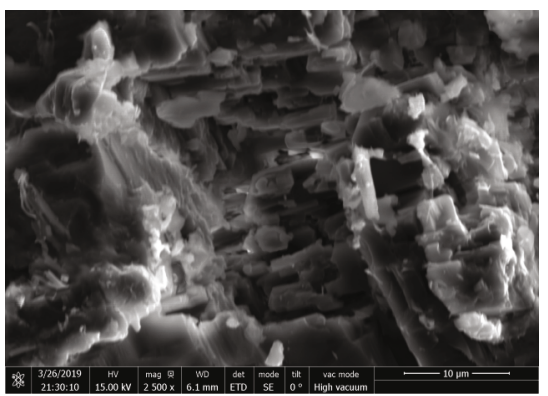

(f)

FIGURE 7: SEM images of sandstones. (a) Sample $4206.1 \mathrm{~m}$, well TZ-4: microcrystalline quartz crystals and illite clays. (b) Sample $4787 \mathrm{~m}$, well YN-2: finely hair-like illite. (c) Sample 5146.8 m, well DB-102: flake illite. (d) Sample 4787 m, well YN2: Fe-calcite encasing illite. (e) Sample $4787 \mathrm{~m}$, well YN-2: illite and chlorite. (f) Sample $4787 \mathrm{~m}$, well YN-2: feldspar dissolution.

originating from the rapid uplift of the Tianshan Mountains. The foreland thrusting activities were dominant, resulting in a large number of thrust nappes and folds in the Kuqa Depression (Figure 1(b)).

The Mesozoic and Cenozoic strata are well preserved in the eastern Kuqa Depression (Figure 2). The Lower Jurassic is dominated by fluvial and deltaic deposits, the Middle Jurassic is dominated by deltaic and lacustrine deposits, and the Upper Jurassic is the combination of alluvial fan, deltaic floodplain, and lacustrine deposits [18-22]. The Lower Jurassic Ahe Formation, the focus of this research, is characterized by the braided deltaic environment $[18,23]$. The sandstones are mainly deposited in braided channels in the delta plain and in distributary channels in the delta front. These channel sand bodies are generally fining up units ranging mainly from gravel-bearing coarse-grained sandstones to finegrained sandstones with minor siltstone and mudstone laminas. The total thickness is about $240-300 \mathrm{~m}$ in the Dibei area with sand fractions of approximately $80-90 \%$.

Source rocks in the eastern Kuqa Depression contain mudstones and coal seams deposited mainly in the Triassic
Huangshanjie and Taliqike Formation and the Jurassic Yangxia and Kezilenuer Formation (Figure 2). The Triassic source rocks have total thickness of less than $582 \mathrm{~m}$; mudstones have total organic carbon (TOC) contents of 0.4\%-24.4\% [25]. The total thickness of the Jurassic source rocks is $202-1381 \mathrm{~m}$; TOC values of mudstones are $0.3 \%-16.4 \%$ [25]. Organic matter is mainly type III kerogen and minor type II kerogen [24, 25]. In the study area, the Jurassic source rocks have Ro values of less than $1.0 \%$, while Ro values of the Triassic source rocks are greater than 1.0\% [25]. The burial history of the study area was characterized by the early long-term shallow burial and late rapid deep burial, and this made the source rocks matured rapidly during late burial [26]. The Jurassic mudstones and the Miocene Jidike Formation gypsum deposits serve as good caprocks for petroleum accumulations (Figure 2).

\section{Samples and Methods}

The conventional logging series of 11 wells in the study area (Figure 1(a)), including natural gamma ray (GR), sonic 


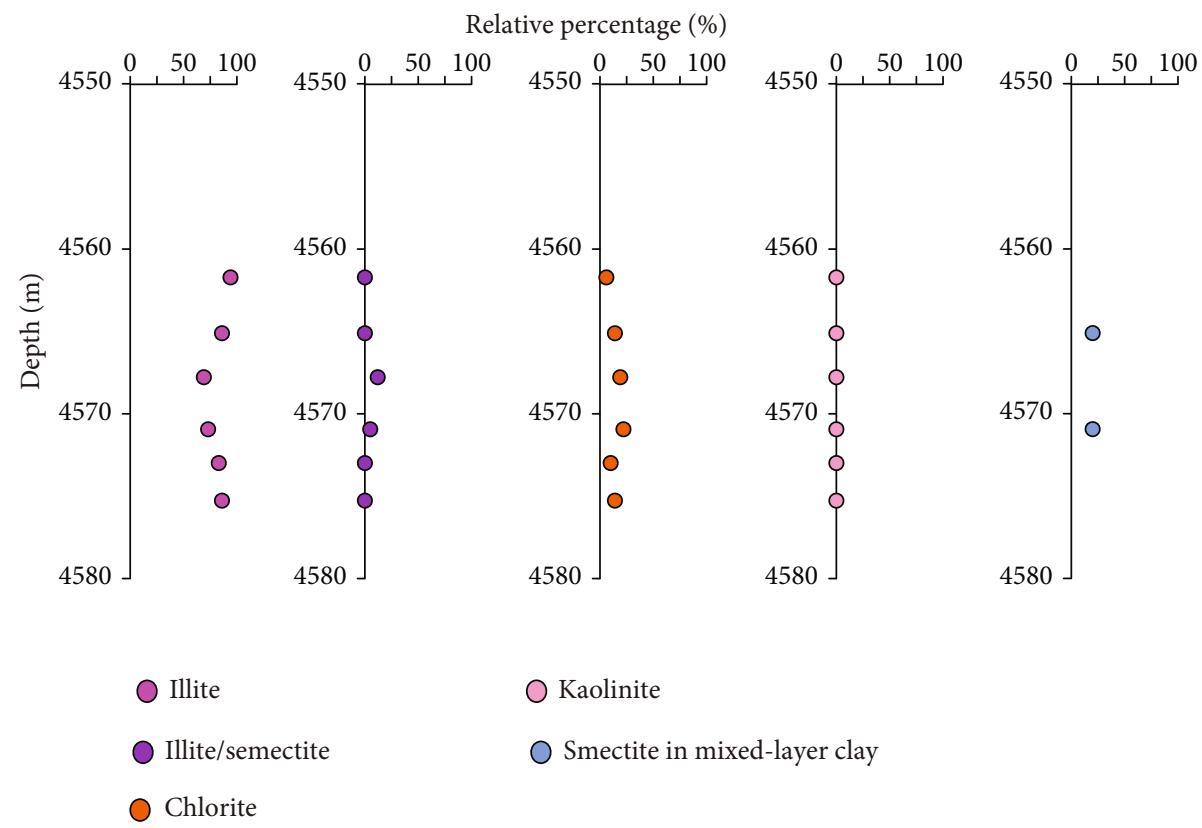

(a)

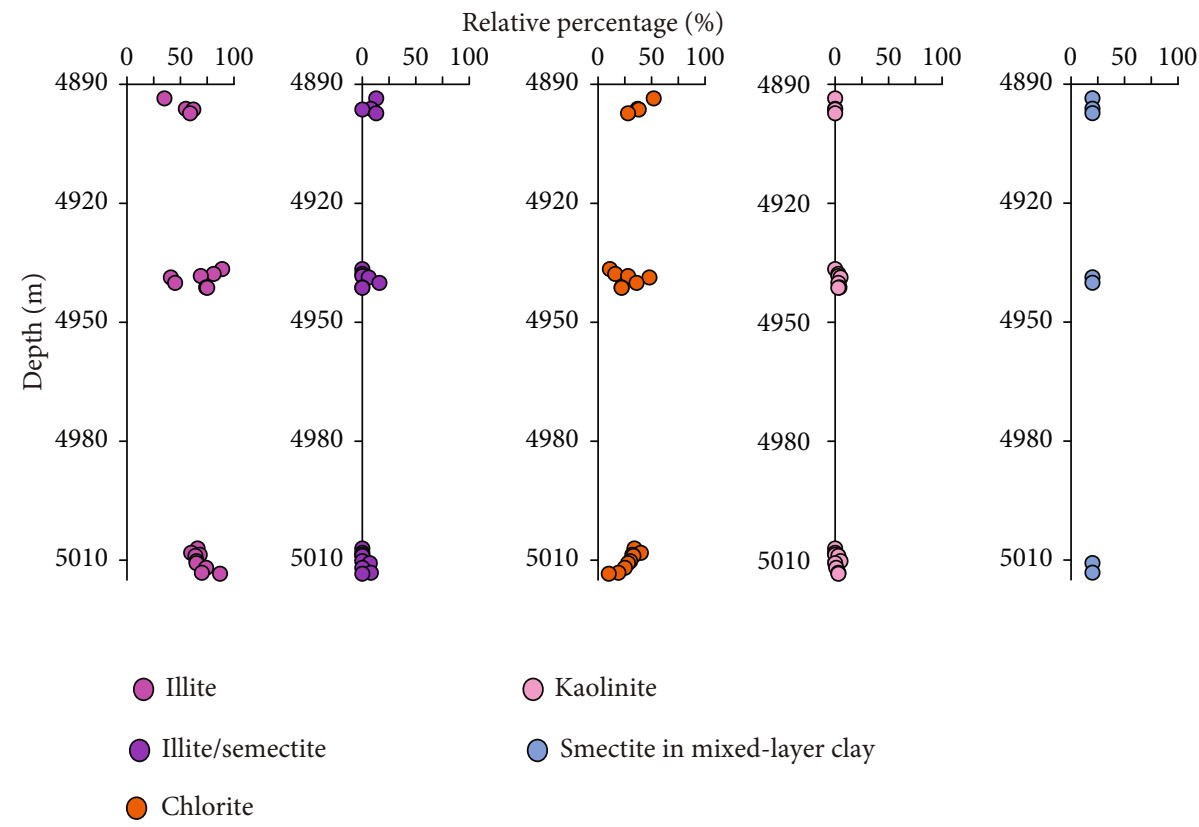

(b)

FIgURE 8: X-ray diffraction clay minerals of (a) well YN-4 and (b) YN-5.

transit time (DT), and deep resistivity (RD), were collected. Four hundred core porosity and permeability measurements were also made. Detailed core descriptions, including petroleum shows, lithology, grain size, and carbonate cementation, were performed in three wells (Figure 3). 32 thin sections were made to determine petrology of sandstones. X-ray diffraction clay mineral analysis data were collected from well YN-4 and YN-5. A scanning electron microscope (SEM) with energy dispersive X-ray spectroscopy (EDS) and backscatter electron (BSE) was used to furthermore identify diagenetic minerals, textural relationships between different minerals, and pore structures. Petrography and microthermometry of fluid inclusions were also conducted. Details regarding sampling and experimental procedures for porosity and permeability measurement, thin section petrology, XRD, SEM and BSE, and fluid inclusion analysis are available in Appendix A.

\section{Results}

4.1. Detrital Texture and Compositions. The sandstones in the Ahe Formation are fine- to coarse-grained sandstones, and most sandstones are medium- to coarse-grained varieties. The roundness of detrital grains varies from subangular 


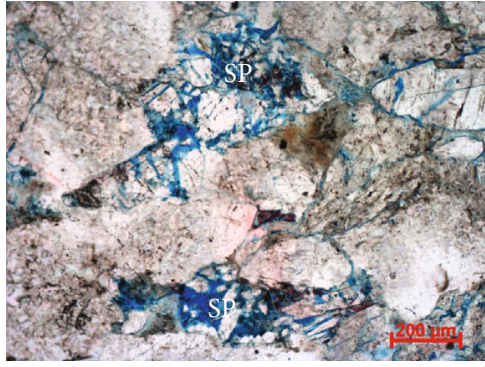

(a)

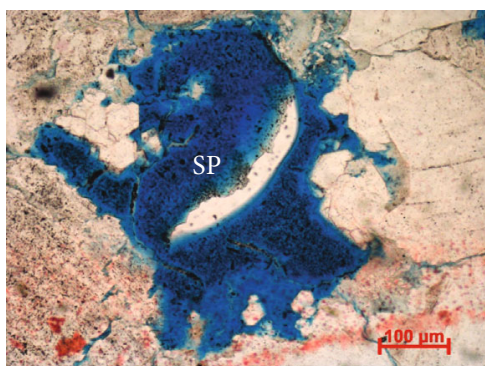

(c)

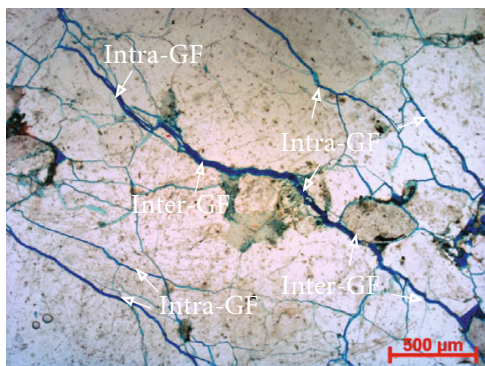

(e)

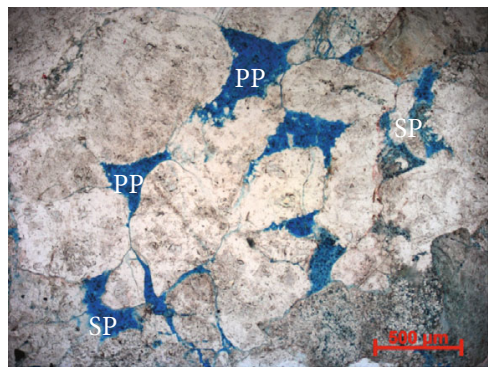

(g)

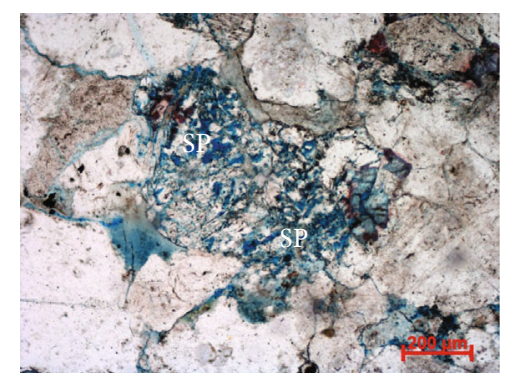

(b)

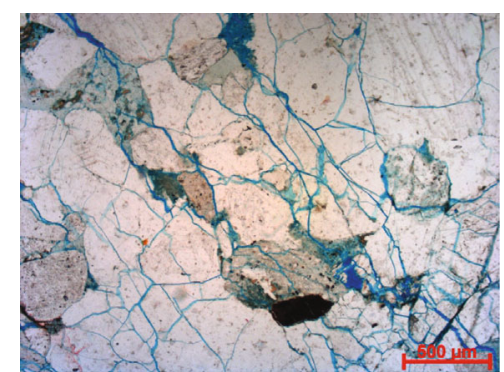

(d)

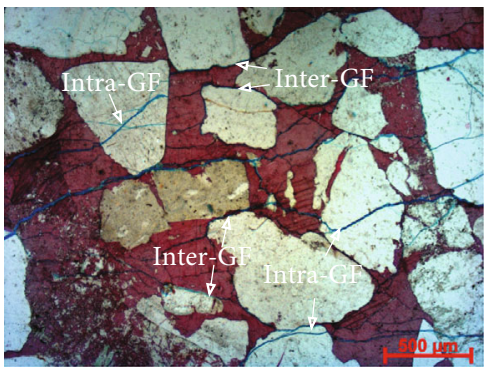

(f)

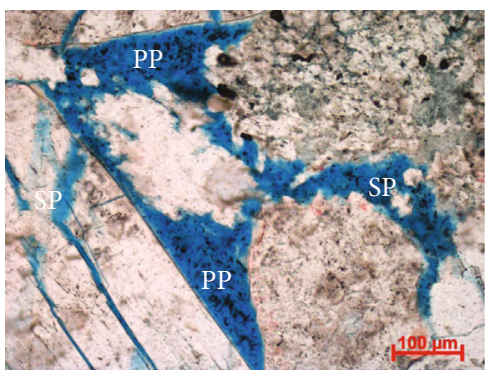

(h)

FIgURE 9: Thin section images of pores in sandstones. (a) Sample $4787 \mathrm{~m}$, well YN-2, plane-polarized light (PPL): dissolution pore. (b) Sample $4787 \mathrm{~m}$, well YN-2, PPL, intragranular dissolved pores. (c) Sample $4203.9 \mathrm{~m}$, well TZ4, PPL: mold pores and quartz crystals. (d) Sample 5029.8 m, well DB-102, PPL: microfractures and dissolution pores. (e) Sample 5029.8 m, well DB-102, PPL: microfractures occurring along boundaries of detrital grains (Inter-GF) and cutting through grains (Intra-GF). (f) Sample 4937.7 m, well DB102, PPL: microfractures occurring along boundaries of detrital grains (Inter-GF) and cutting through grains (Intra-GF) and cement. (g) Sample $4203.5 \mathrm{~m}$, well TZ4, PPL: intergranular pores and minor dissolution pores. (h) Sample $4203.5 \mathrm{~m}$, well TZ-4, PPL: intergranular pores and dissolution pores. Primary porosity (PP) and secondary porosity (SP).

to subrounded. The sorting is moderate, but the conglomeratic sandstone is poorly sorted.

The sandstones are primarily litharenite and minor feldspathic litharenite (Figure 4(a)). They are in a state of low compositional maturity. The following numbers refer to proportions of the detrital fraction of the rock. Quartz gains range from $18 \%$ to $72 \%$ with an average of $46 \%$. K-feldspar grains are less than $18 \%$ with an average of $8 \%$, and plagioclase grains are less than $10 \%$ with an average of $1 \%$. Lower-grade metamorphic rock fragments are the most important component of rock fragments (Figure 4(b)) and range between 5\% and $65 \%$ with an average of $25 \%$. The lower-grade metamorphic rock fragments are schist, phyllite, slate, and metamorphic siltstone fragments. Volcanic rock fragments have contents of $1 \%-40 \%$ with an average of $11 \%$, and sedimentary rock fragments are less than $24 \%$ with an average of $8 \%$. In addition, 


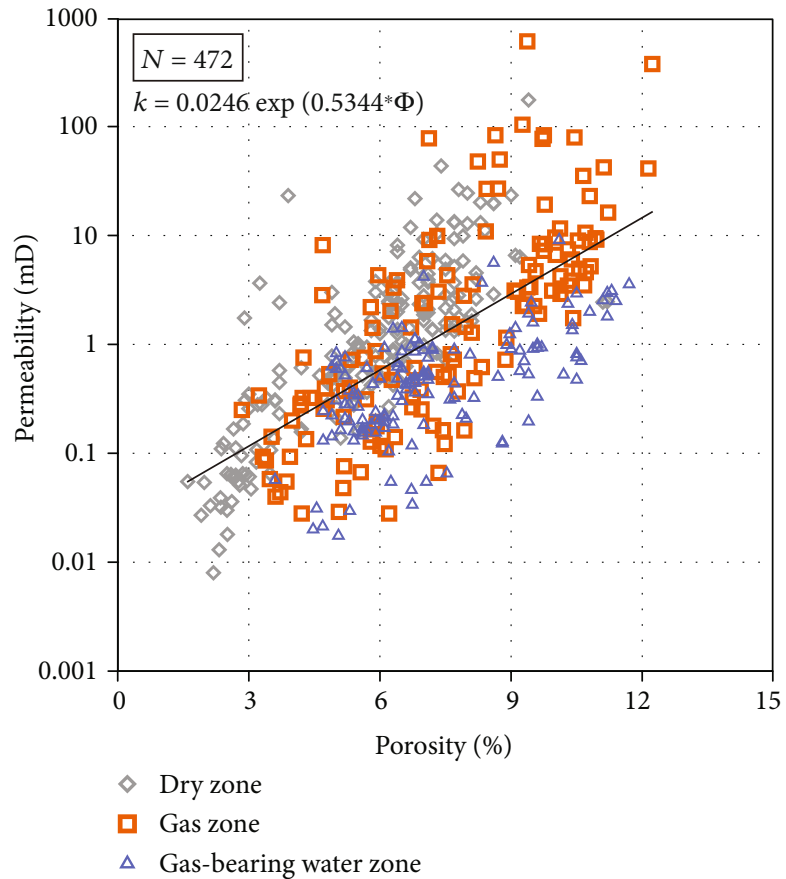

(a)
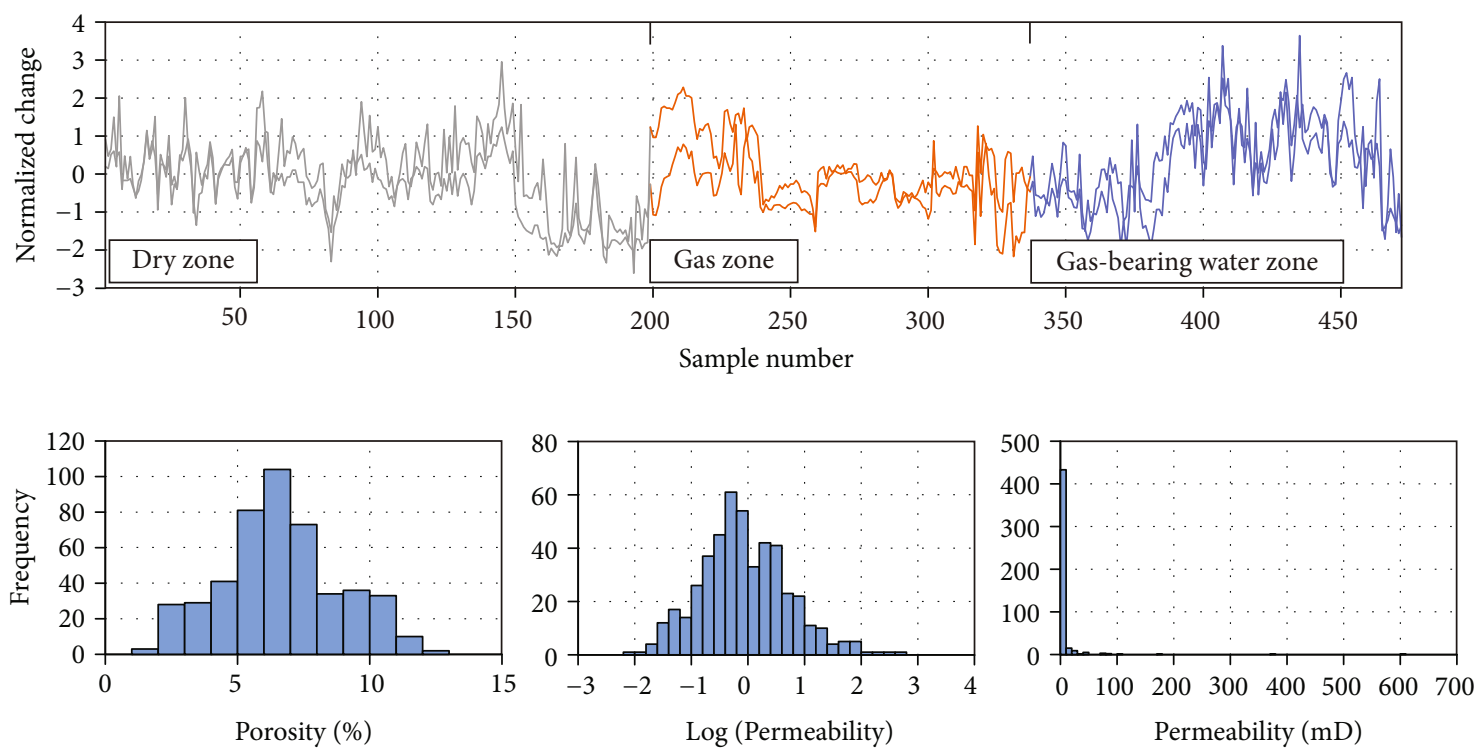

(b)

Figure 10: Continued. 


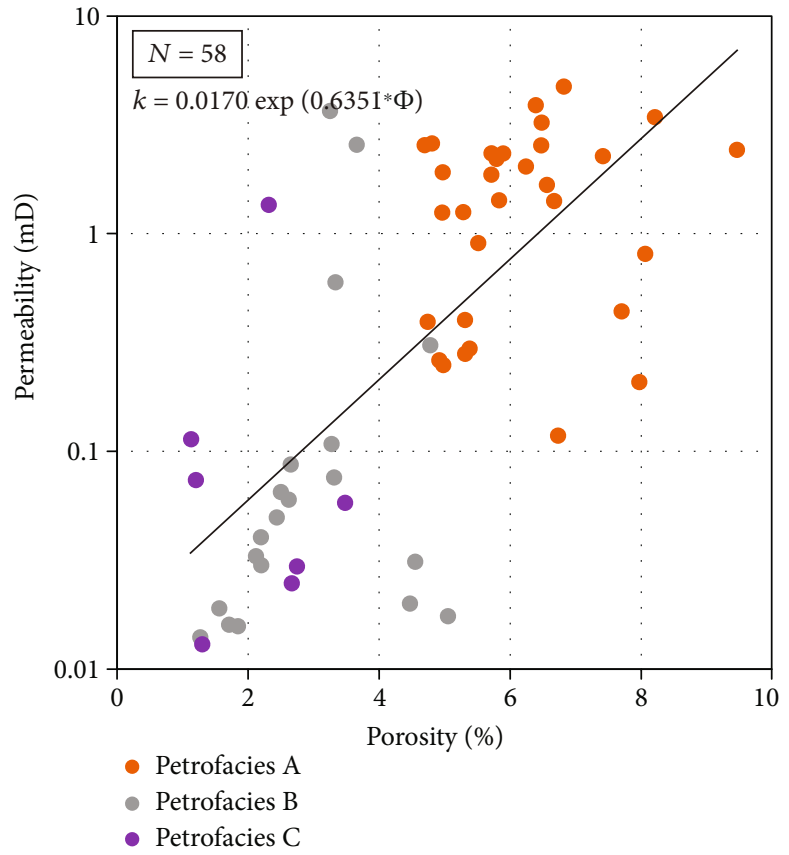

(c)
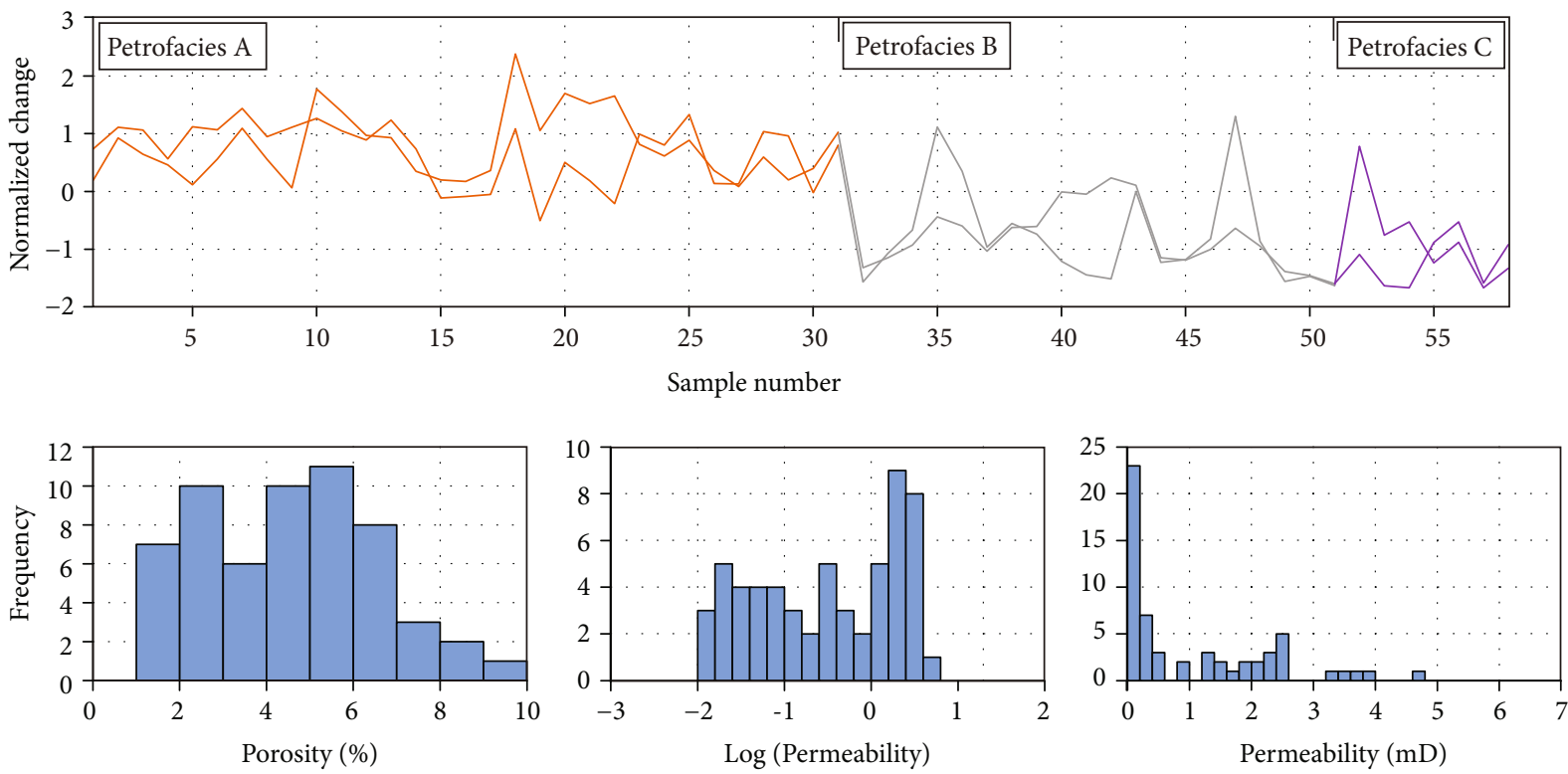

(d)

Figure 10: $(\mathrm{a}, \mathrm{c})$ Plot of porosity vs. permeability. Petrofacies A: ductile-lean sandstone, Petrofacies B: ductile-rich sandstone, and Petrofacies C: tightly calcite-cemented sandstone. (b, d) Frequency histograms of core porosity, log (permeability) and permeability, and overlay of porosity (thin line) and log (permeability) (thick line) as functions of sample number. Both are normalized to zero mean and unit variance.

small amounts of muscovite fragments are present in the sandstones with an average of $2 \%$ and locally up to $15 \%$.

Detrital matrix in the sandstones is mainly clay matrix and has a content of $2 \%-25 \%$ of the whole rock, with an average of $7 \%$.

\subsection{Diagenesis}

4.2.1. Compaction. The gradual increase in overlying strata loads during burial can cause detrital grains severely deformed, rotated, dislocated, and crushed, resulting in the loss of intergranular porosity. Most ductile grains (obviously deformed lower-grade metamorphic rock fragments, altered volcanic rock fragments, and mudstone fragments) are observed in thin sections to be severely deformed around rigid grains such as quartz and feldspar by mechanical compaction and to be squeezed into intergranular pores (Figure 5(a)). Because of the variability in sandstone composition and texture, the degree of ductile compaction in the sandstones is differential. The relatively finer-grained, clay 


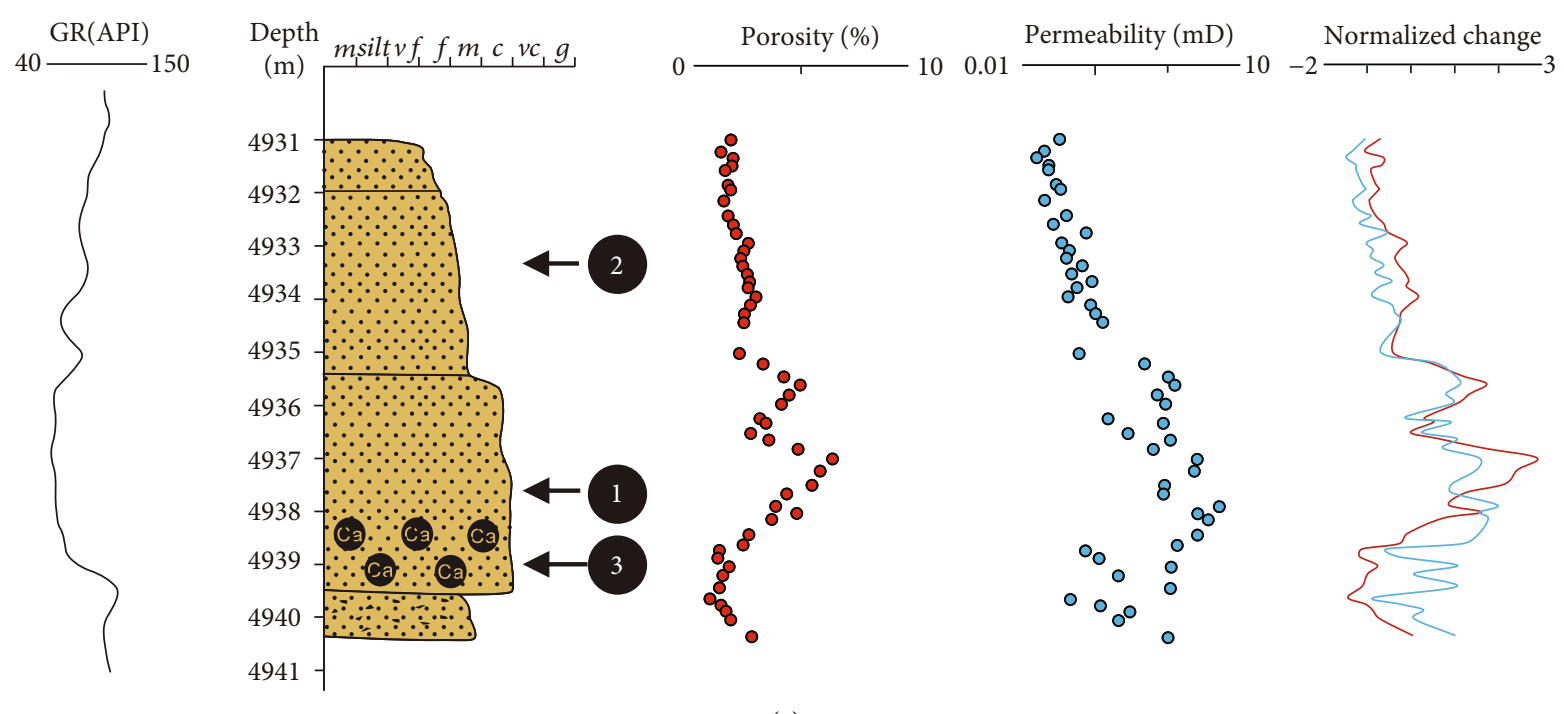

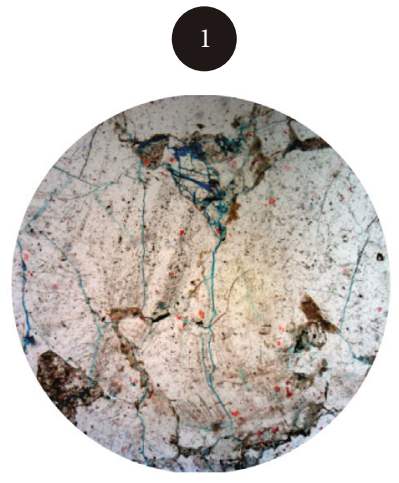

Ductile-lean standstone

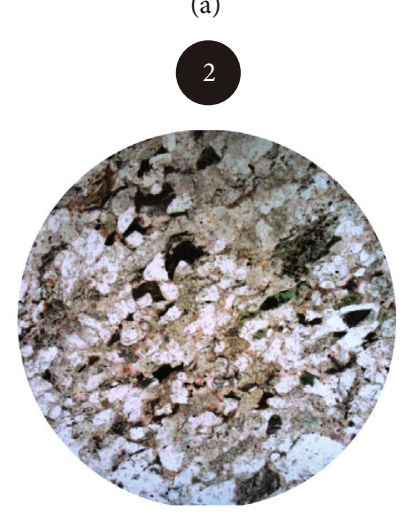

Ductile-rich standstone

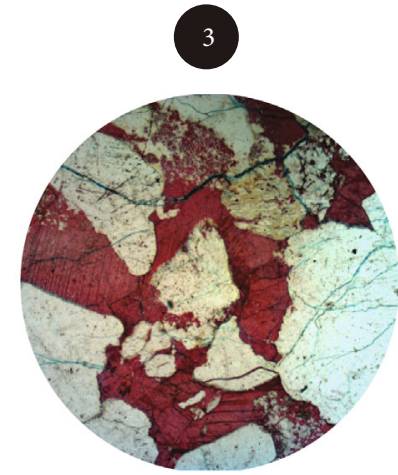

Tightly calcite-cemented sandstone

(b)

Figure 11: (a) Typical vertical lithology profile and gamma ray log and porosity and permeability distribution in well DB102. Porosity (red line) and log (permeability) (blue line) are plotted along sample depth in normalized form (zero mean and unit variance). (b) Petrographic characteristics of various petrofacies.

TABLE 1: Petrographic characteristics of different petrofacies in the study area.

\begin{tabular}{|c|c|c|c|c|c|c|c|c|c|}
\hline Petrofacies & $\begin{array}{c}\text { Quartz } \\
\text { grains (\%) }\end{array}$ & $\begin{array}{l}\text { Feldspar } \\
\text { grains (\%) }\end{array}$ & $\begin{array}{l}\text { Micas } \\
(\%)\end{array}$ & $\begin{array}{c}\text { Rock } \\
\text { fragment } \\
(\%)\end{array}$ & $\begin{array}{c}\text { Total authigenic } \\
\text { minerals }(\%)\end{array}$ & $\begin{array}{l}\text { Detrital } \\
\text { matrix (\%) }\end{array}$ & $\begin{array}{c}\text { Fe- } \\
\text { calcite } \\
(\%)\end{array}$ & $\begin{array}{c}\text { Ductile } \\
\text { grains (\%) }\end{array}$ & $\begin{array}{c}\text { Median } \\
\text { size }(\mathrm{mm})\end{array}$ \\
\hline $\begin{array}{l}\text { Ductile-lean } \\
\text { sandstone }\end{array}$ & $35-47$ & $3-12$ & $0-1$ & $46-60$ & $1-4$ & $4-8$ & $0-2$ & $27-44$ & $0.27-0.54$ \\
\hline $\begin{array}{l}\text { Ductile-rich } \\
\text { sandstone }\end{array}$ & $37-45$ & $3-8$ & $0-1$ & $50-56$ & $0-3$ & $10-15$ & $0-1$ & $40-50$ & $0.06-0.26$ \\
\hline $\begin{array}{l}\text { Tightly calcite- } \\
\text { cemented sandstone }\end{array}$ & $28-42$ & $2-12$ & $0-1$ & $46-70$ & $22-29$ & $2-8$ & $22-27$ & $7-11$ & $0.48-0.72$ \\
\hline
\end{tabular}

matrix-rich sandstones have a higher degree of compaction than those coarser-grained sandstones having less matrix (Figures 5(b) and 5(c)). In addition, in tightly calcitecemented sandstones, framework grains have a floating appearance and show weak compaction (Figure 5(d)).

4.2.2. Cementation. Carbonate cement is widely distributed in the Ahe Formation, mainly consisting of Fe-calcite, anker- ite, and siderite. Contents of Fe-calcite are up to $27 \%$ of the whole rock. Based on its microtexture and occurrence, two types of Fe-calcite are recognized in the sandstones. The one type represents a poikilotopic texture, almost completely filling intergranular pores and minor replacing grains and clay matrix. Framework grains show a floating appearance indicating precipitation before significant compaction (Figure $5(\mathrm{~d})$ ). The other type displays a rather patchy 


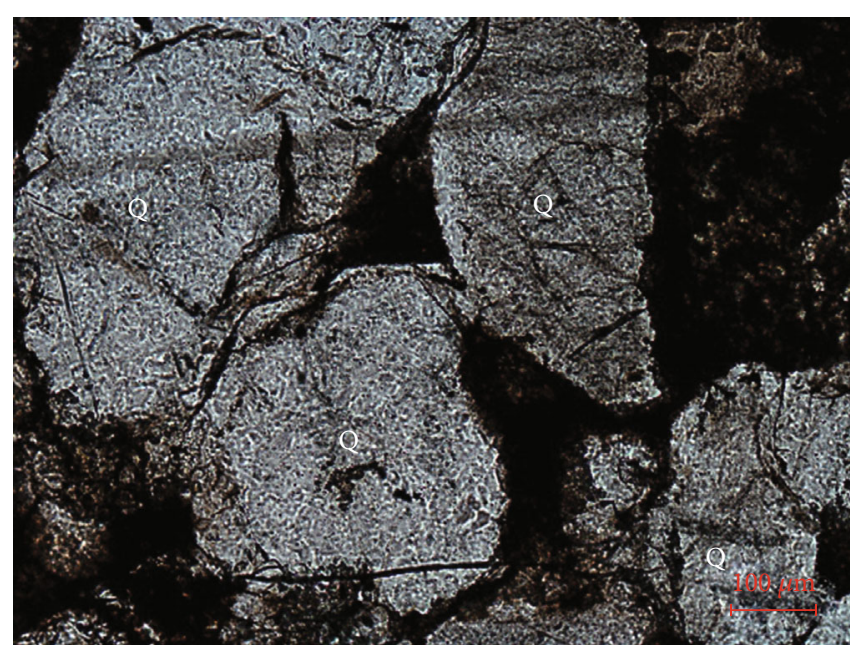

(a)

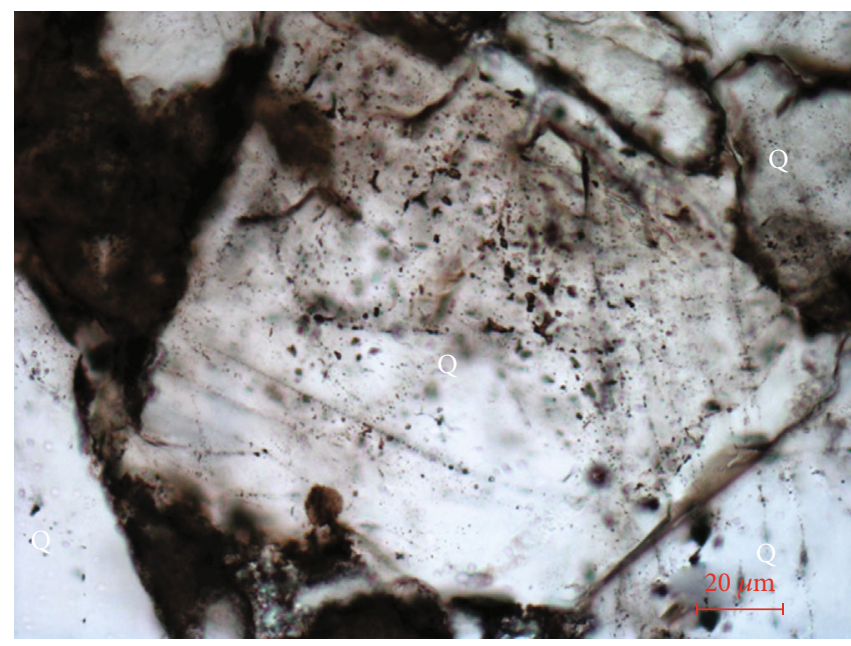

(c)

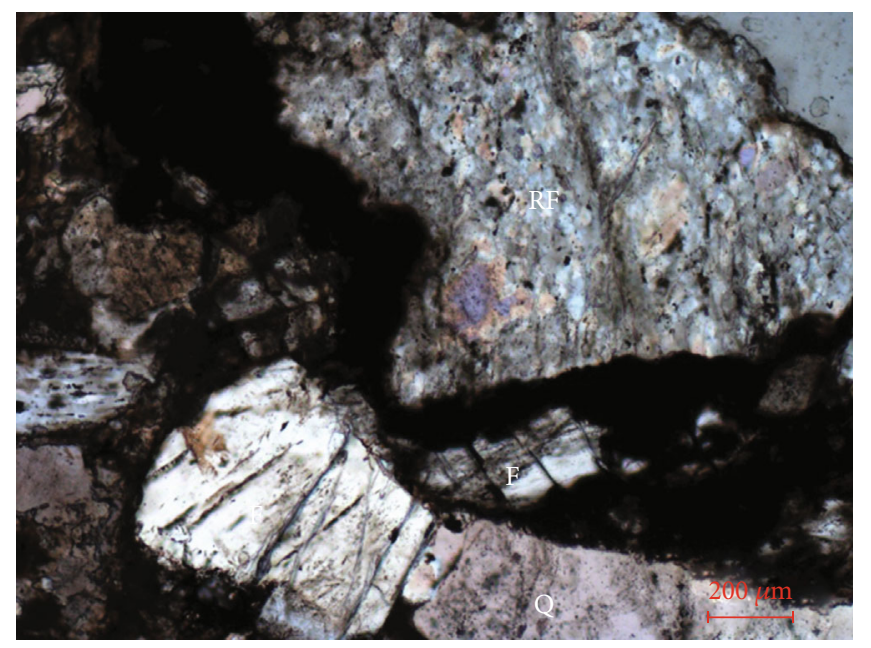

(e)

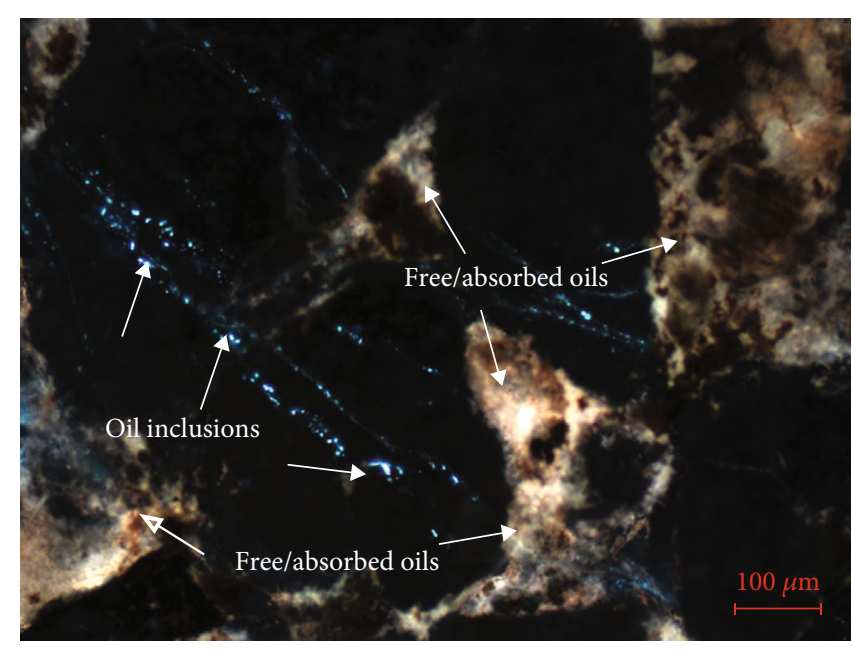

(b)

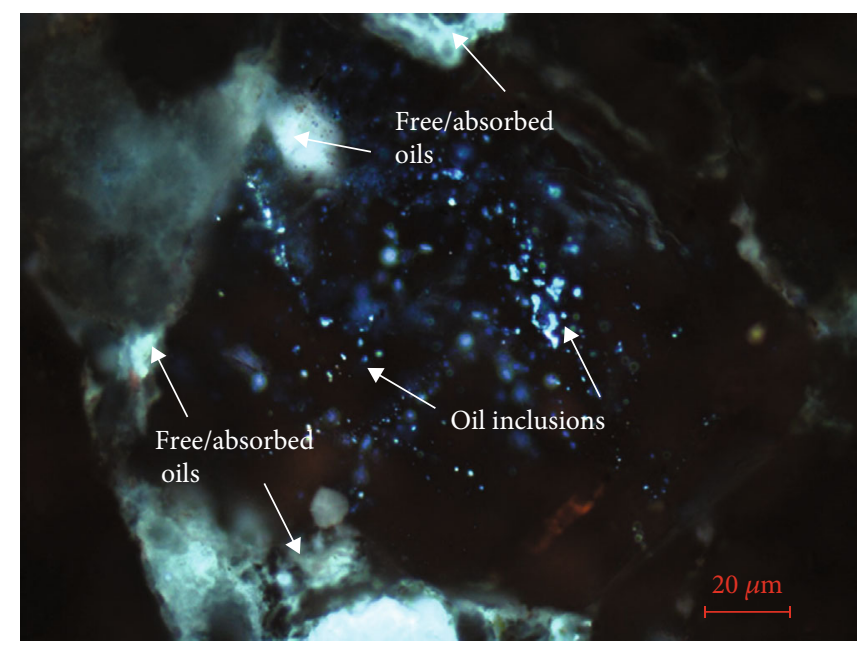

(d)

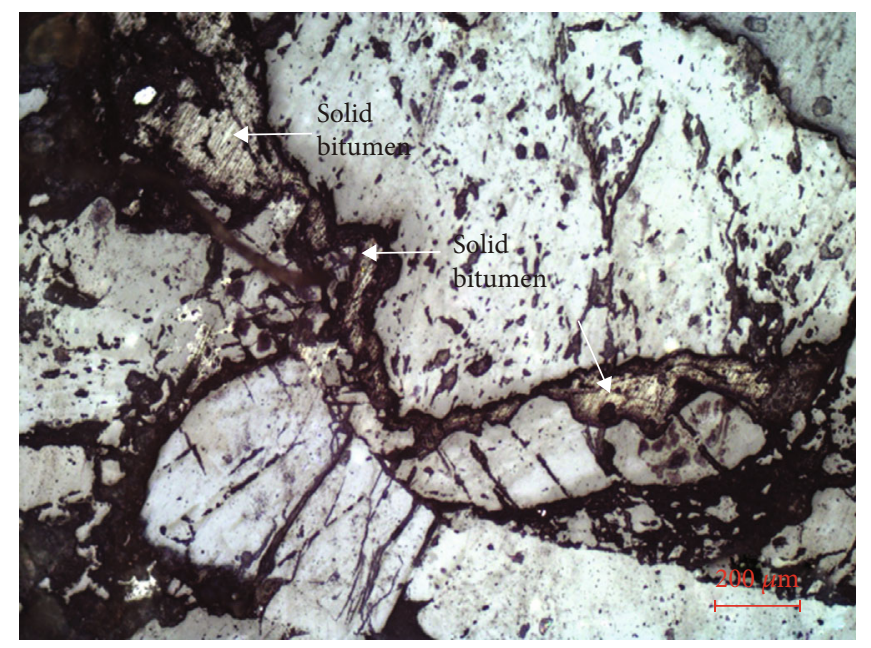

(f)

FIgURE 12: Continued. 


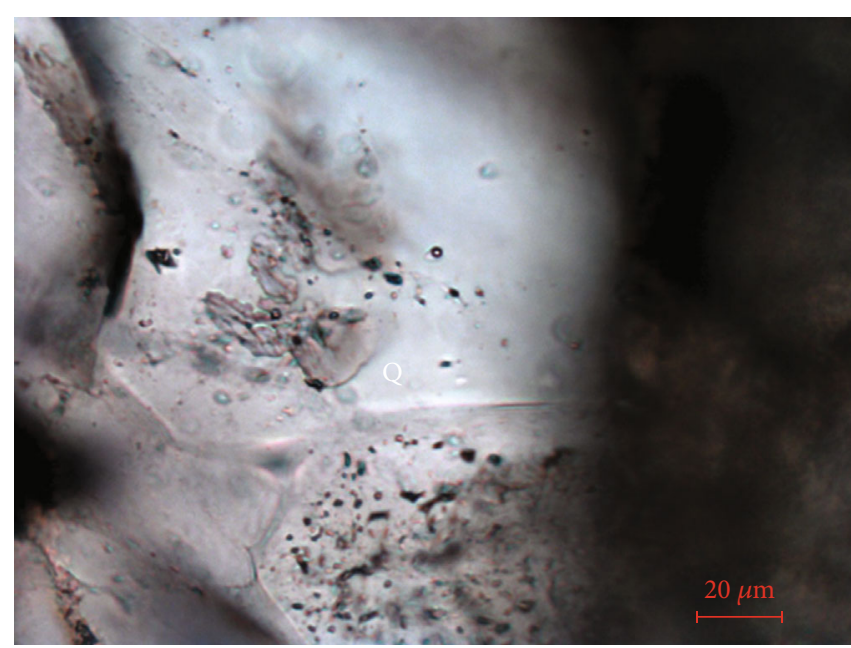

$(\mathrm{g})$

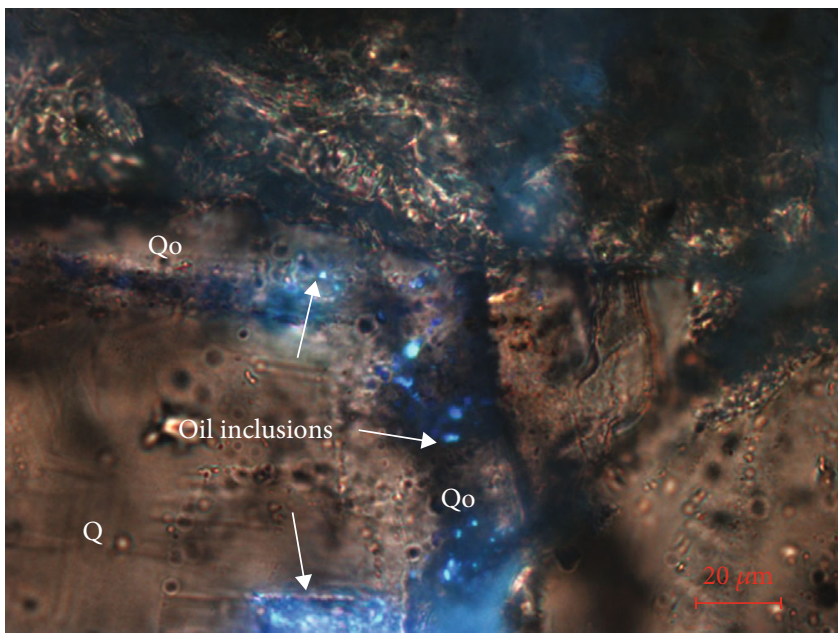

(i)

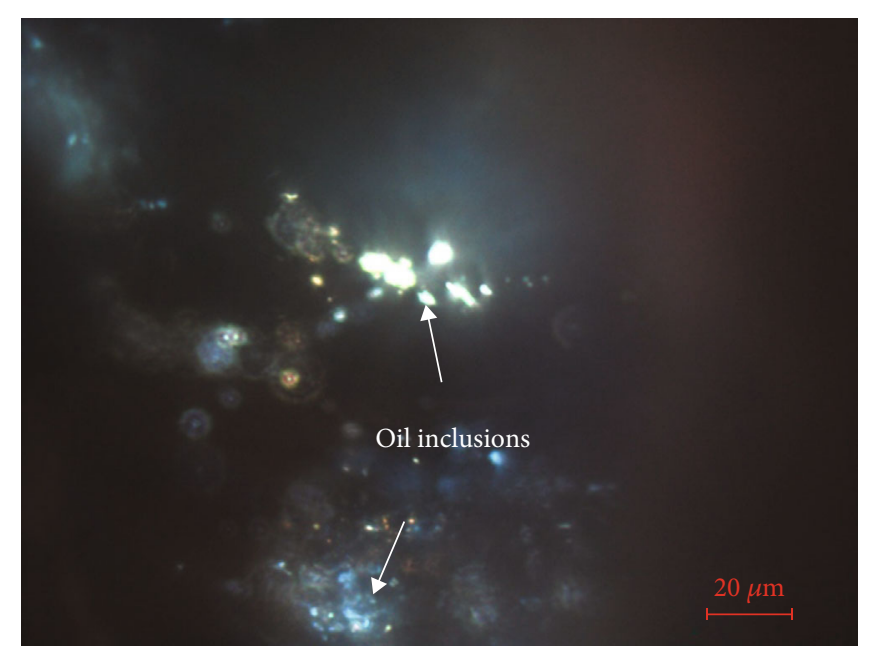

(h)

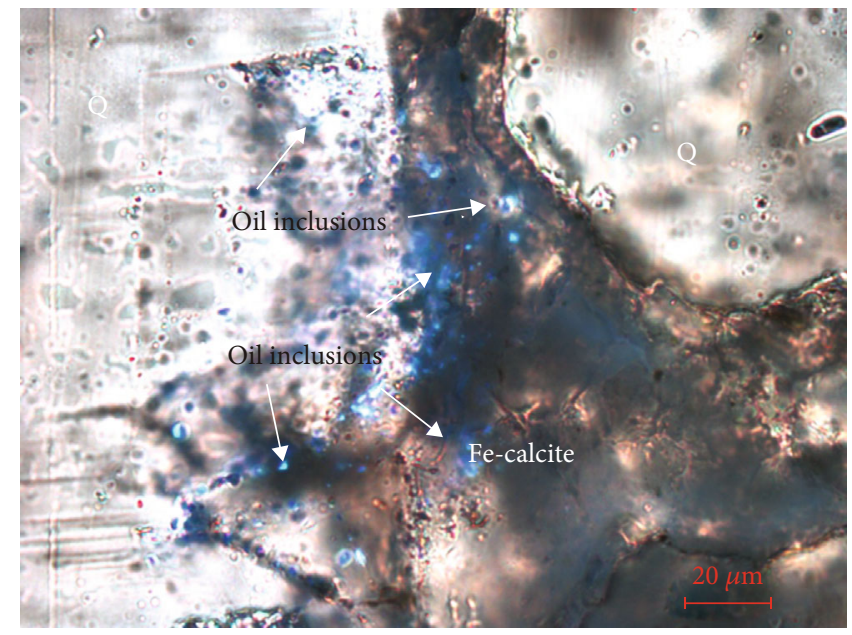

(j)

Figure 12: Thin section images of pore bitumens and oil inclusions. (a, b) Sample $4935.4 \mathrm{~m}$, well DB-102, plane-polarized light (PPL) and ultraviolet light (UV): yellow fluorescing pore-free and absorbed oils and blue fluorescing oil inclusions occurring along healed microfractures cutting through grains and terminating at detrital quartz margin. (c, d) Sample $4787 \mathrm{~m}$, well YN-2, PPL and UV: blue fluorescing pore-free and absorbed oils and blue fluorescing inclusions occurring along quartz lithoclase. (e, f) Sample 4842.6 m, well YN2, PPL and reflect light: intergranular pore filled with solid bitumens. (g, h) Sample $4842.6 \mathrm{~m}$, well YN-2, PPL and UV: yellow and blue fluorescing oil inclusions in quartz grains. (i) Sample $5055 \mathrm{~m}$, well DB-102, UV: blue fluorescing oil inclusions in detrital quartz and quartz overgrowths, indicating that oil charge occurred after or was synchronous with quartz overgrowths. (j) Sample $5055 \mathrm{~m}$, well DB102, UV: blue fluorescing oil inclusions in quartz grain and Fe-calcite cement, indicating oil charge after or synchronous with Fe-calcite cement. Q: quartz grain; F: feldspar grain; RF: rock fragment; Qo: quartz overgrowth.

cementation and fills intergranular pores and dissolution pores and replaces framework grains (Figures 5(e) and 6(a)). Based on petrographic evidence, the patchy calcite postdates and/or is synchronous with quartz overgrowths (Figure 5(f)). The content of ankerite is less than $3 \%$. Ankerite cement also has a rather patchy and local cementation, filling pores and replacing detrital grains. The ankerite postdates quartz overgrowths (Figure $5(\mathrm{~g})$ ). Siderite is rare, generally less than $1 \%$, and filling dissolution pores (Figures 6(a) and 6(b)).

Quartz cement is generally less than 5\% and mainly occurs as quartz overgrowths (Figures 5(f)-5(h)). Quartz overgrowths predate and/or is synchronous with patchy $\mathrm{Fe}$ calcite and ankerite (Figures 5(f) and 5(g)). In places, quartz cement can also be observed to fill pores in the form of stubby bipyramidal crystals (Figure 7(a)).

X-ray diffraction analysis (Figure 8) indicates that clay minerals in the sandstones are illite (average 69\%), chlorite (average 26\%), and minor amounts of illite/smectite (average $4 \%$ ) and kaolinite (average 1\%). Mixed-layer illite/smectite is approximately $70 \%$ illite. Illite clays have finely hair-like and flake morphology (Figures 7(b) and 7(c)) and occur as grain coats or pore fills (Figures 6(c) and 6(d)). Illite is generally intergrown with quartz crystals (Figure $7(\mathrm{a})$ ) and is engulfed by Fe-calcite (Figures 6(c) and 7(d)). Chlorite typically occurs as finely platelets and is intergrown with illite (Figures 6(d)$7(\mathrm{e}))$. In finer-grained, clay matrix-rich sandstones, illite is dominated by the flake morphology (Figure $7(\mathrm{c})$ ). 


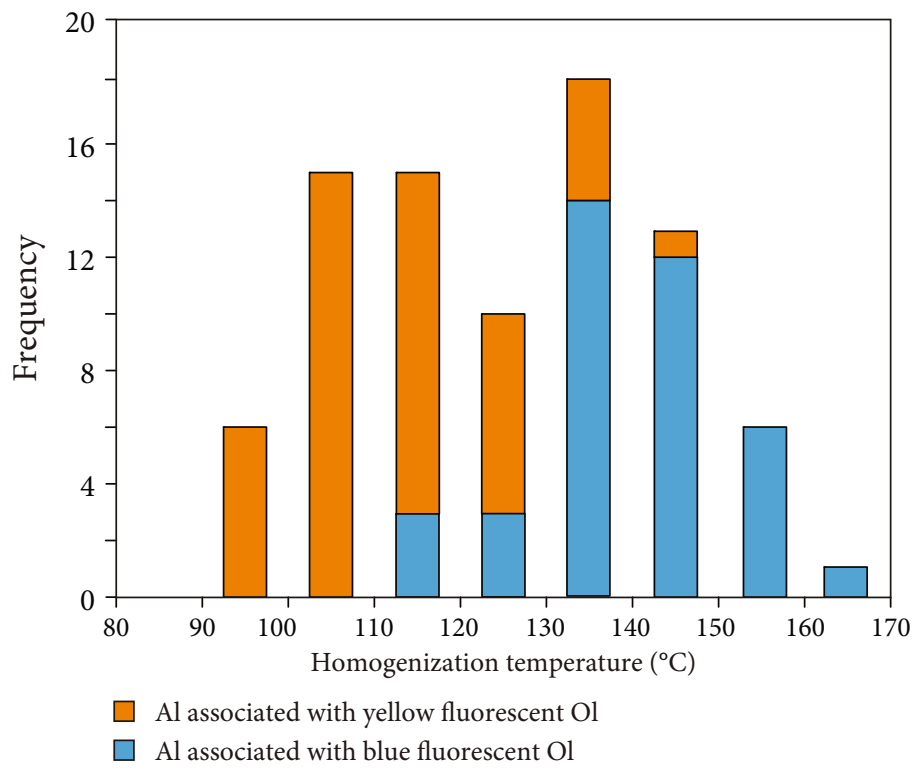

FIGURE 13: Histograms of homogenization temperatures for aqueous inclusions (AI) that are coeval with oil inclusions (OI).

4.2.3. Dissolution. Dissolution is mainly confined to the coarser-grained sandstones containing less clay matrix. Dissolution is very common within feldspar grains, rock fragments, and clay matrix. Cements are rarely dissolved. Intragranular dissolved pores and mold pores are formed by part or complete dissolution of framework grains (Figures 5(c), 5(e), 6(f), 7(f), and 9(a)-9(c)). Parts of dissolution pores are filled with carbonates and quartz crystals (Figures 5(e), 6(a)-6(c), and 9(c)).

4.2.4. Fracturing. Microfractures are commonly developed in the sandstones, including those occurring along boundaries of framework grains, those cutting through grains, and those cutting through clay matrix or cements (Figures 9(d)-9(f)). Microfractures have radius values usually less than $50 \mu \mathrm{m}$, and they have thin porosity generally less than $0.1 \%$, locally up to $0.5 \%$. Propagation paths of microfractures are affected by detrital composition of sandstones and diagenetic types and severity. Petrographic observations indicate the following: those microfractures along grain boundaries accounting for $40 \%$, those cutting through rigid quartz and feldspar grains account for $39.2 \%$, those cutting through ductile rock fragments make up 9.6\%, those cutting through clay minerals make up 5.6\%, those cutting through other cements make up $0.8 \%$, and those cutting through pores account for $4.8 \%$.

4.3. Petrographic Pore Types and Distribution. The sandstones contain primary intergranular pores (Figures $9(\mathrm{~g})$ and $9(\mathrm{~h})$ ), intragranular dissolved pores and mold pores (Figures 5(c), 5(e), 6(f), 7(f), and 9(a)-9(c)), microfracture (Figures 9(d)-9(f)), and intercrystalline pores within clay minerals (Figures 7(a)-7(e)). The coarser-grained, matrixpoor sandstones contain primary pores and dissolution pores. They have thin section porosity of $0.9 \%-2.6 \%$ with an average of $1.6 \%$. Primary intergranular porosity is less than $0.5 \%$; dissolution porosity is $0.9-2.1 \%$ with an average of $1.5 \%$; microfractures have thin section porosity less than
$0.1 \%$. Sporadic dissolution pores are found in the relatively finer-grained, matrix-rich sandstones with thin section porosity less than $1 \%$. Tightly calcite-cemented sandstones contain few pores. Intercrystalline pores within clay minerals can provide storage spaces, but they have small pore radius (mostly micron) and are not well connected with other large primary intergranular pores and dissolved pores.

4.4. Reservoir Quality. The above analyses show that the Ahe Formation sandstones have highly heterogeneous reservoir quality. This is also supported by core-analysis petrophysical properties. The sandstones have porosities in the range from $1.6 \%$ to $12.2 \%$, averaging $6.7 \%$, and they have permeabilities ranging between 0.008 and $605 \mathrm{mD}$, averaging $0.8710 \mathrm{mD}$ (Figure 10(a)). Generally, porosity and permeability properties in gas zones are better for production than those in gas-bearing water zones and dry zones. However, the properties in sandstones vary greatly in gas zones, gas-bearing water zones, and dry zones. It is noted that the porosity and permeability values in this data set have a normal and lognormal distribution, respectively; spatial changes in porosity are invariably associated with changes in the logarithm of permeability (Figure 10(b)).

4.5. Classification of Sandstone Petrofacies. Based on sandstone composition and texture, diagenetic types and processes, and pore types and distribution, three sandstone petrofacies are defined in the Ahe Formation: ductile-lean sandstone, ductile-rich sandstone, and tightly calcitecemented sandstone (Figure 11). Petrographic characteristics of different petrofacies are summarized in Table 1.

Ductile-lean sandstones are mainly medium- to coarsegrained sandstones with median grain size values of 0.27 $0.54 \mathrm{~mm}$. The content of detrital matrix is low (4.0-8.0\%). The sandstone petrofacies display moderate compaction, and the contents of ductile grains are 27.0-44.0\%. Cement varieties include $\mathrm{Fe}$-calcite, ankerite, siderite, authigenic 


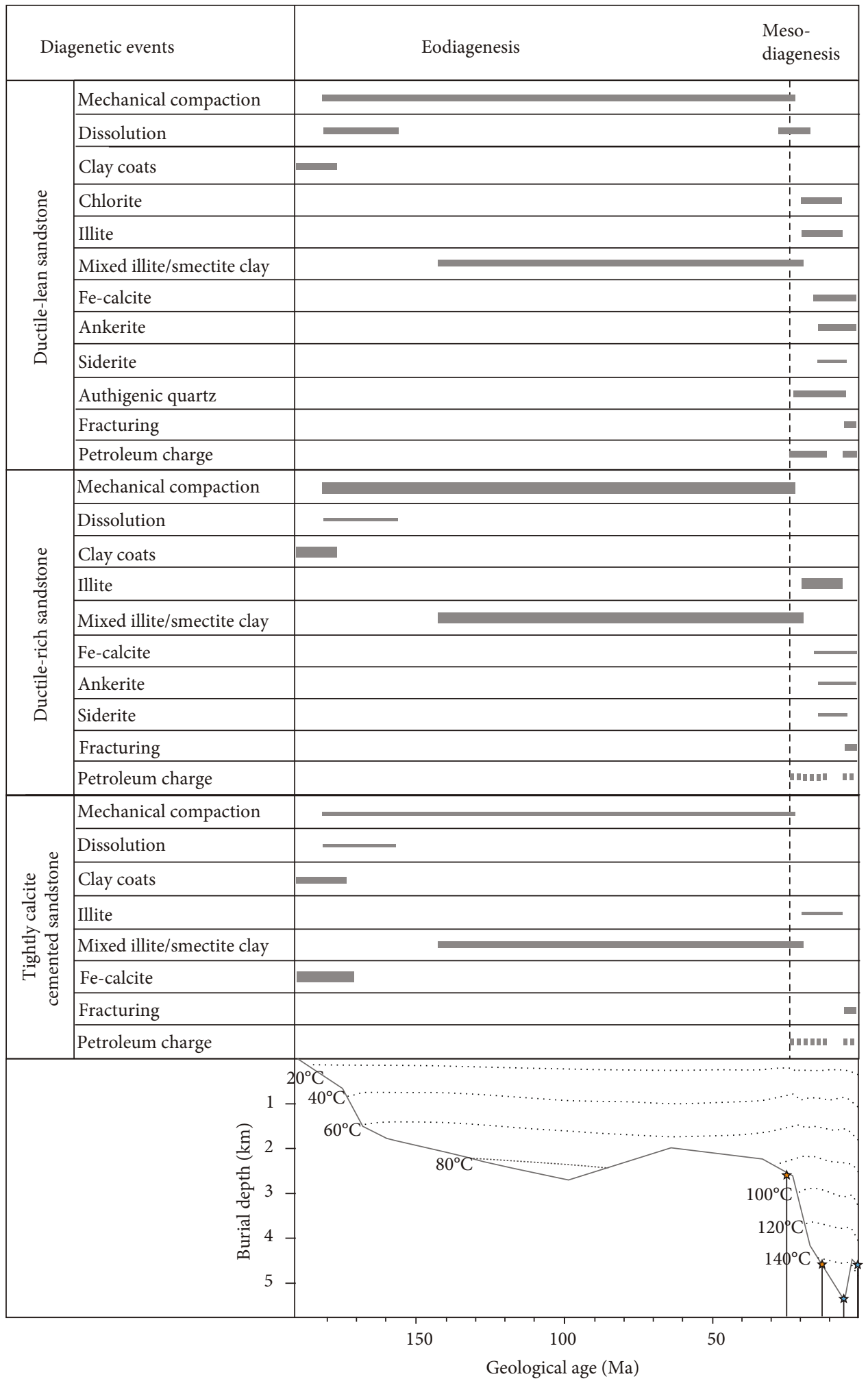

Early charge

Late charge

FIGURE 14: Contrasting diagenetic sequences of different petrofacies in the Ahe Formation. 

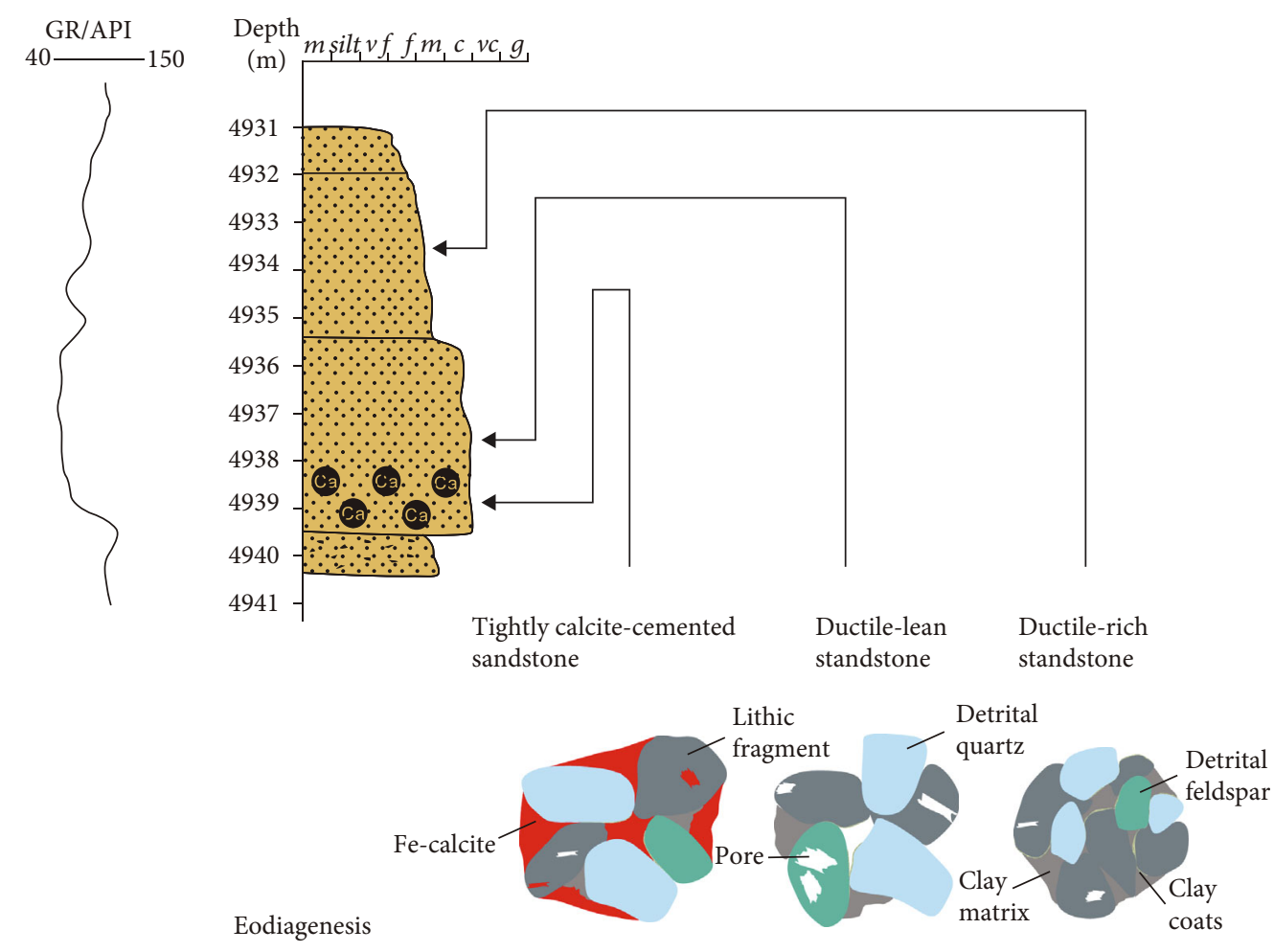

Mesodiagenesis

Before early charge
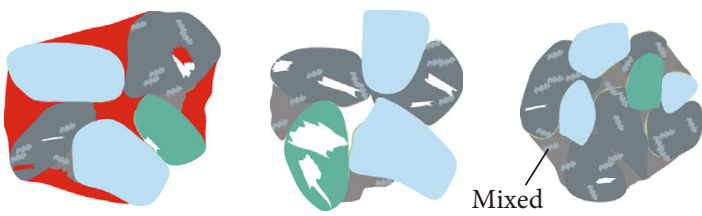

illite/smectite
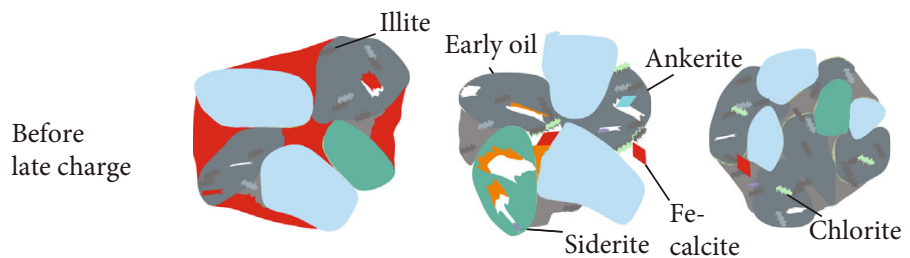

Late

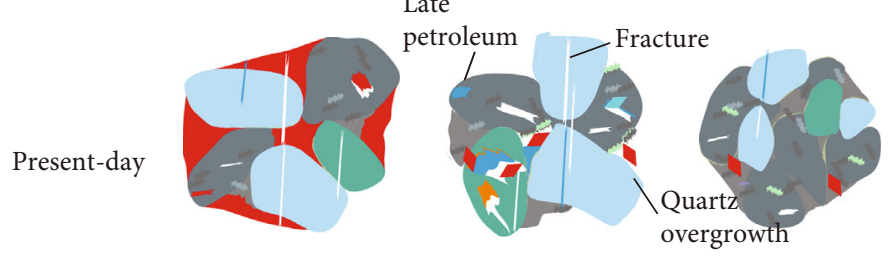

FIGURE 15: Contrasting diagenesis evolution models of different petrofacies.

quartz, and clay minerals, but the total amount of the cements is low (1.0\%-4.0\%). Dissolution of feldspar and rock fragments is very common in the petrofacies. Thin section porosity values range from $0.9 \%$ to $2.6 \%$, with an average of $1.6 \%$. Primary intergranular pores, intragranular dissolution pores, and fractures are commonly developed. The petrofacies have good petrophysical properties, with porosities of $4.7 \%-9.5 \%$ (average $6.2 \%$ ) and permeabilities of 0.118 $4.724 \mathrm{mD}$ (average $1.139 \mathrm{mD}$ ) (Figure 10(c)).

Ductile-rich sandstones are fine- to medium-grained sandstones with median grain size values of $0.06-0.26 \mathrm{~mm}$.
Clay matrix is abundant in the petrofacies, and it accounts for $10.0-15.0 \%$. The petrofacies display strong ductile compaction, and the contents of ductile grains are $40.0-50.0 \%$. Ductile grains are strongly deformed along rigid grains such as detrital quartz and even squeezed into intergranular pores. Carbonate minerals have a local cementation, and quartz cementation is hardly developed in the petrofacies. Clay minerals are dominated by "honeycomb" textured, finely flake illite clays. Sporadic dissolution pores occur in the petrofacies, and thin section porosity is less than $1 \%$. Petrophysical properties of the petrofacies are relatively poorer, with 
porosities of $1.3 \%-5.1 \%$ (average $2.9 \%$ ) and with permeabilities of $0.014-3.650 \mathrm{mD}$ (average of $0.069 \mathrm{mD}$ ) (Figure $10(\mathrm{c})$ ).

Tightly calcite-cemented sandstones are constrained to medium- to coarse-grained sandstones with a median grain size of $0.48-0.72 \mathrm{~mm}$. They have a low degree of ductile compaction with floating framework grains. The cementation is characterized by $\mathrm{Fe}$-calcite cements. The Fe-calcite has a poikilotopic texture filling pores and replacing grains and clay matrix, and it accounts for $22.0-27.0 \%$ of the whole rock. In the petrofacies, dissolution of feldspar and rock fragments is very rare, and sporadic dissolution pores are recognized. The petrofacies have porosities ranging from $1.1 \%$ to $3.5 \%$, (average 2.9\%) and have permeabilities ranging from 0.013 to $1.354 \mathrm{mD}$ (average $0.067 \mathrm{mD}$ ) (Figure 10(c)).

\section{Discussion}

5.1. Petroleum Charge Dating. Pore-free oils and adsorbed oils are common in ductile-lean sandstones. They display yellow and blue-white fluorescence (Figures 12(a)-12(d)). In addition, brown solid bitumens are also recognized in pores (Figures 12(e) and 12(f)). Pore-free oils, adsorbed oils, and solid bitumens are rare in ductile-rich sandstones and tightly calcite-cemented sandstones.

Oil inclusions are commonly seen in ductile-poor sandstones. They are elliptical, elongated, and irregular in shape and are often less than $5 \mu \mathrm{m}$. Oil inclusions mainly are distributed along healed microfractures cutting through or terminated within quartz grains (Figures 12(a)-12(d), 12(g), and $12(\mathrm{~h}))$. Minor oil inclusions are distributed in quartz overgrowths and carbonate cement (Figures 12(i) and 12(j)). These oil inclusions have yellow and blue fluorescence.

Aqueous inclusions associated with yellow fluorescent oil inclusions have homogenization temperatures of mainly 90$140^{\circ} \mathrm{C}$, while homogenization temperatures of aqueous inclusions associated with blue fluorescent oil inclusions are 110$160^{\circ} \mathrm{C}$ (Figure 13 ).

The homogenization temperature is a minimum trapping temperature of fluid inclusions and represents the minimum precipitation temperature of the host mineral [28]. The measured homogenization temperatures can be related to the burial-thermal history to reveal the timing of petroleum charge. In most geological cases, pressure correction is required to estimate the true trapping temperature. In hydrocarbon-bearing sandstones, the concentration of soluble hydrocarbons approximates or reaches a saturation level in pore waters [29]. Therefore, the measured homogenization temperatures are approximately equivalent to the true trapping temperatures without pressure correction.

Based on the homogenization temperature distribution of aqueous fluid inclusions (converted to age via the thermal history), petroleum charge can be divided into two stages: $25 \mathrm{Ma}$ to $12 \mathrm{Ma}$ and $5 \mathrm{Ma}$ to the present day (Figure 14). These results are consistent with the results of $\mathrm{Li}$ et al. [30, 31] and Shi et al. [32]. They indicated that since the deposition of the Miocene Jidike Formation (23 Ma-), the Triassic source rocks began to enter the mature stage; when the Pliocene Kuqa Formation deposited (5 Ma-), the Triassic source rocks reached the peak of gas generation and migration,

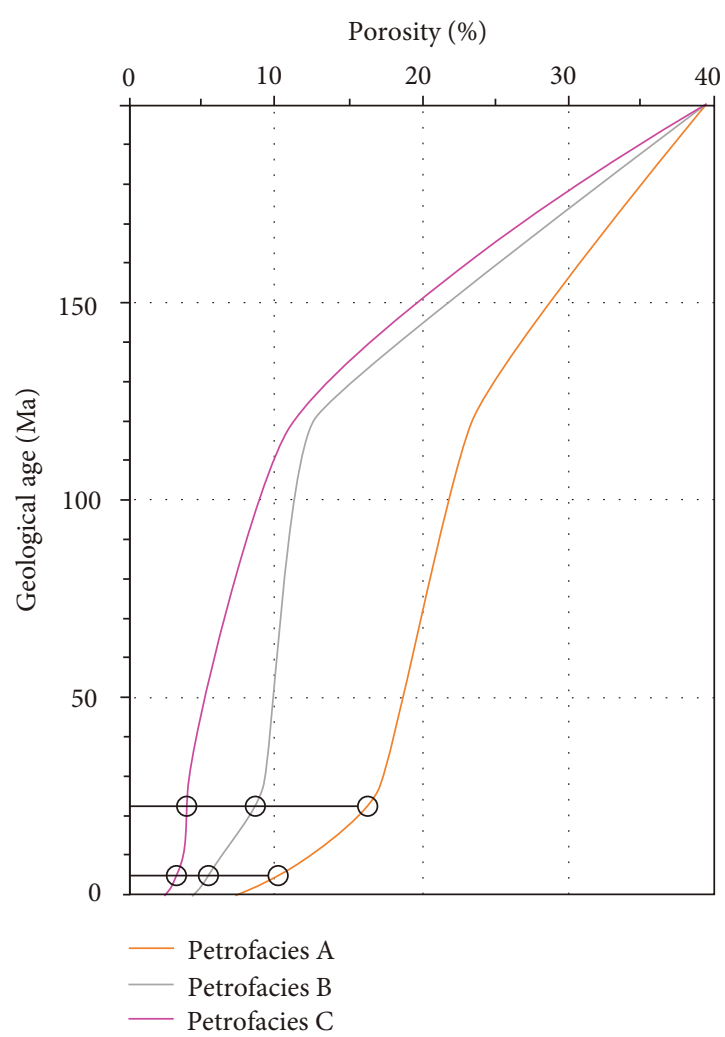

FIgURE 16: Porosity evolution models of different petrofacies. Petrofacies A: Ductile-lean sandstone, Petrofacies B: ductile-rich sandstone, and Petrofacies C: tightly calcite-cemented sandstone.

and the Jurassic source rocks entered the mature stage to generate oil and gas.

5.2. Differential Sandstone Diagenetic and Petroleum Charge History. Combination of thin section, SEM and BSE observations give insights into textural relationships between different diagenetic minerals, which can aid in establishing the diagenetic sequence. The main eodiagenetic alterations includes the following: (1) mechanical compaction of ductile grains, (2) minor early clay coats and pore-filling clays, (3) early Fe-calcite precipitation, and (4) initial dissolution of detrital feldspar and rock fragments (Figure 14). Mesodiagenetic alterations includes the following: (1) late dissolution of detrital grains, (2) alteration of smectite into illite, precipitation of illite and small amounts of chlorite, (3) authigenic quartz precipitation, (4) late Fe-calcite, ankerite and siderite precipitation, and (5) petroleum charge (Figure 14). However, diagenetic evolutions of different sandstone petrofacies experienced contrasting pathways due to variabilities in primary texture and compositions of sandstones.

5.2.1. Eodiagenesis. The Ahe Formation experienced the long-term shallow burial and eodiagenesis since the deposition through the Paleogene (Figure 14). Detrital compositions and texture of sandstones and original porosity and permeability determine the degree and distribution of eodiagenetic alterations [10, 33]. The relatively finer-grained, matrix-rich ductile-rich sandstones underwent a higher 


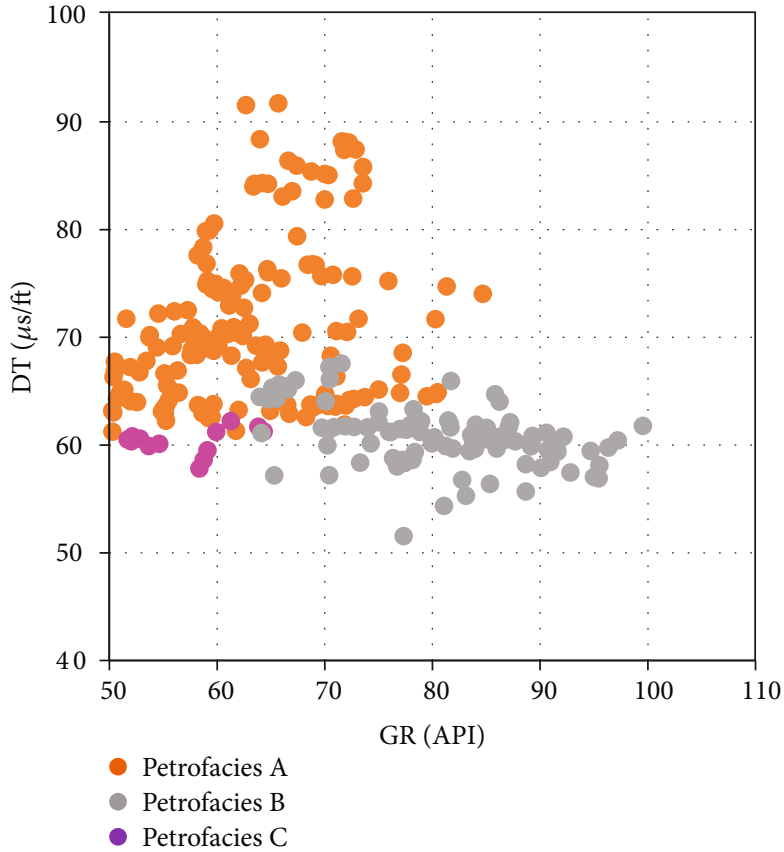

(a)

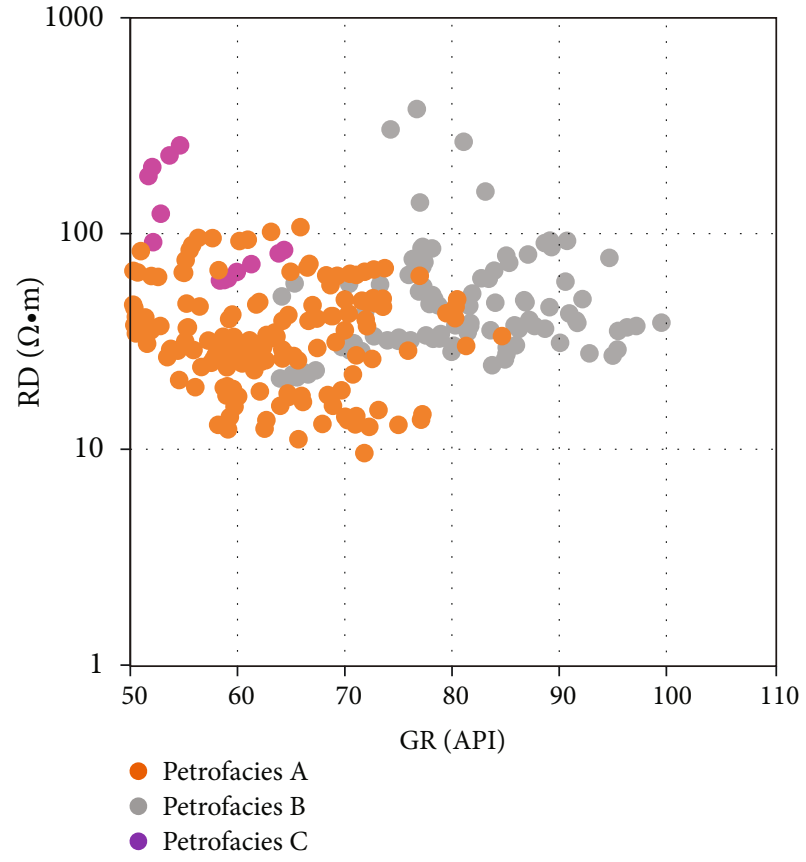

(b)

FIgure 17: GR value versus DT and RD value. Petrofacies A: ductile-lean sandstone, Petrofacies B: ductile-rich sandstone, and Petrofacies C: tightly calcite-cemented sandstone.

degree of mechanical compaction relative to the coarsergrained ductile-lean sandstones containing less matrix (Figures 14 and 15). Argillaceous ductile grains were easily deformed and became smeared over surfaces of rigid grains and squeezed into pore throats leading to significant loss of intergranular porosity. Unstable detrital feldspar and rock fragments were easily dissolved by meteoric water under near-surface conditions in the early stage of eodiagenesis. Moreover, coals in the Yangxia Formation overlying the Ahe Formation were subject to oxidative degradation or peatification and produced organic acids with much $\mathrm{CO}_{2}[34$, 35], which also promoted dissolution of detrital feldspar and rock fragments.

Grain-coating clays are illite, and they occur tangentially to grain surfaces (Figures 6(c) and 6(d)). The clays are very common in ductile-rich sandstones. These textual characteristics indicate an infiltrated origin, ultimately detrital origin $[36,37]$. EDS analysis indicates (Figure 6(d)) that the graincoating illite is associated with small amounts of mixedlayer illite/smectite clays and chlorite. In addition, the morphology of the grain-coating illite, in places, is similar to smectite, indicating that the smectite precursors were partially or completely altered into illite. This is supported by the presence of mixed-layer clay minerals as shown X-ray diffraction analysis (Figure 8).

Fe-calcite in tightly calcite-cemented sandstones represents a poikilotopic texture, filling most of intergranular pores; framework grains have a floating appearance with the presence of undeformed ductile grains. These petrographic evidences indicate that the Fe-calcite precipitated before significant compaction (Figure 5(c)). Rossi et al. [37] reported that the $\mathrm{Fe}$-calcite has $\delta^{13} \mathrm{C}$ values of $-5.5-3.6 \%$, reflecting mixed sources of dissolved carbon from soilderived bicarbonate and the oxidation of $\mathrm{C}_{3}$ and $\mathrm{C}_{4}$ plants during early diagenesis [38]. The source of $\mathrm{Fe}^{2+}$ in $\mathrm{Fe}$ calcite is linked to dissolution of Fe-rich, metamorphic, and volcanic rock fragments. EDS analysis indicates that argillaceous rock fragments contain abundant Fe (Figure 6(e)).

5.2.2. Mesodiagenesis. Since the deposition of the Miocene Jidike Formation, the Ahe Formation underwent rapid subsidence and burial and entered the mesodiagenetic stage (Figure 14). In the late Oligocene, the Triassic source rocks entered the threshold of hydrocarbon generation [31, 32]. The thermal degradation of organic matter released a large amount of organic acids and $\mathrm{CO}_{2}$ followed or accompanied by oil generation [38-40]. Dissolution of feldspar and rock fragments continued in ductile-lean sandstones. Petrographic evidence for the late dissolution is that some dissolved feldspar and rock fragments have delicate and complete structures (Figures 6(f) and 7(f)). In places, dissolved pores are filled with late patchy carbonate minerals and quartz crystals (Figures 5(e), 6(a)-6(c), and 9(c)). If formed during the early diagenesis, most of the delicate dissolved grains would be destroyed during the subsequent burial.

Authigenic quartz began to precipitate during the mesodiagenetic stage. The dissolution of feldspar and replacement by clays can provide a source of $\mathrm{SiO}_{2}$ for quartz cement. This possible source is supported by the convincing petrographic evidence that quartz crystals occur in dissolved feldspar pores (Figure 9(c)) and coexist with illite clays (Figure 7(a)). Alteration of smectite into illite in interbedded mudstones can also release silica into pore water $[41,42]$. Illite and chlorite also 


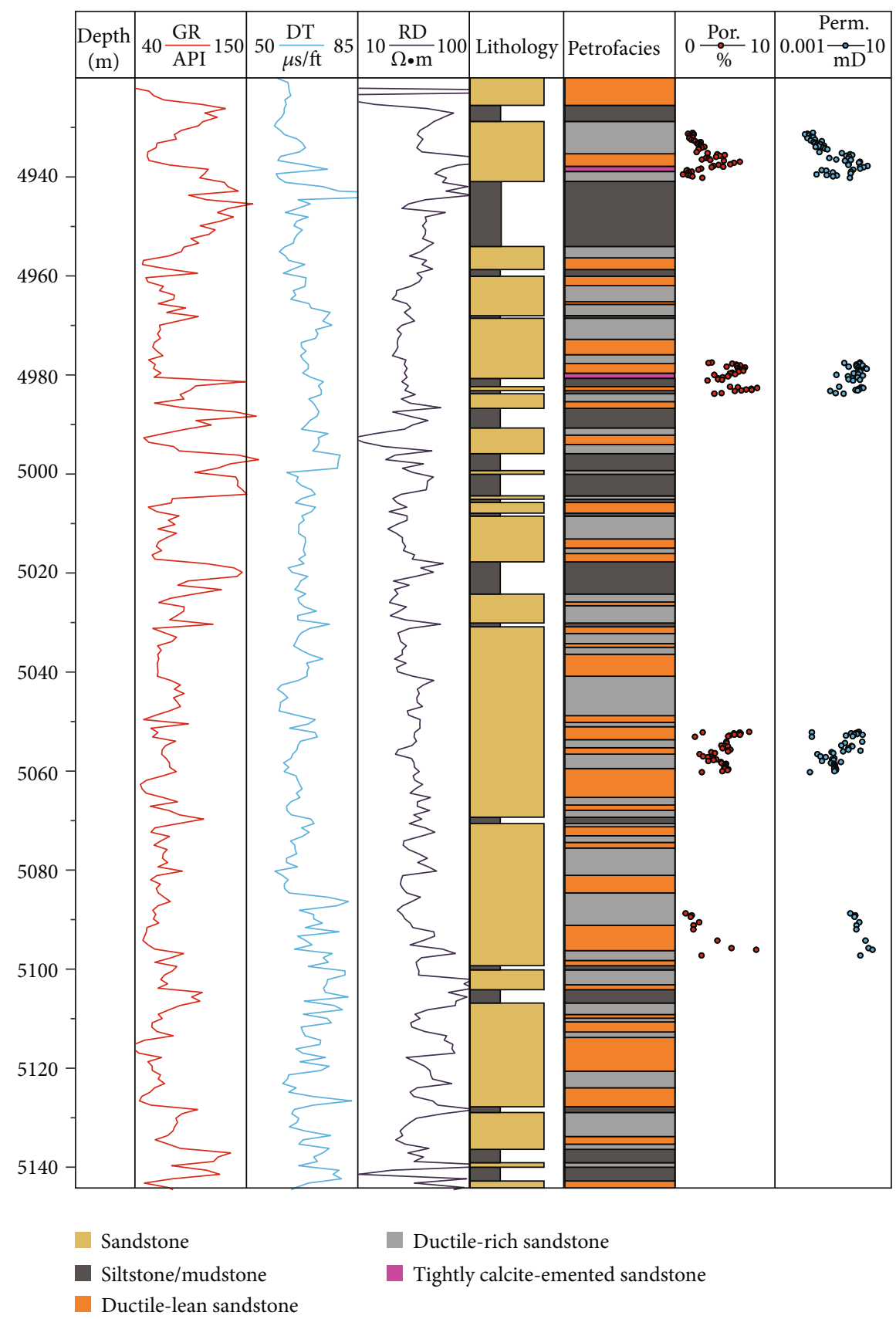

FIGURE 18: Typical vertical profile of well DB-102 showing distribution of sandstone petrofacies.

precipitated in this stage. Illite, formed by the illitization of smectite in the clay matrix, often has the "honeycomb" texture of the smectite precursors and has finely flake morphology (Figures 7(a) and 7(c)). The hair-like illite (Figures 7(a) and 7(b)) was formed by the dissolution of argillaceous rock fragments. EDS analysis of illite indicates small amounts of $\mathrm{Fe}$, indicating the presence of chlorite (Figure 7(b)). In petrographic observations, this mixture of illite and chlorite is in direct contact with $\mathrm{Fe}$ - and $\mathrm{K}$-rich clays, and the outer edge of the Fe- and K-rich clays passes into illite and chlorite filling pores (Figures 6(c) and 6(d)). This Fe- and K-rich clay may be recrystallized rock fragments. Fe-calcite, ankerite, and siderite began to precipitate at this stage. Zhang et al.
[43] indicated that the late Fe-calcite and ankerite have $\delta$ ${ }^{13} \mathrm{C}$ values of $-6.4 \%$ to $-10.4 \%$. $\mathrm{Ni}$ and $\mathrm{Li}$ [44] reported that the Fe-calcite has $\delta^{13} \mathrm{C}$ values of -6.0 to $-18.9 \%$. This indicates a carbon source from the decarboxylation of organic matter [45].

At this stage, early oils and acidic fluids were mainly constrained in ductile-lean sandstones (Figure 15). On the contrary, ductile-rich sandstones became tight due to strong compaction in the early diagenesis. They were hardly charged by early oils and acidic fluids and were dominated by solidphase alteration of smectite into illite. Tightly calcite cemented sandstones also underwent minimal influx of acid fluids and petroleum. 

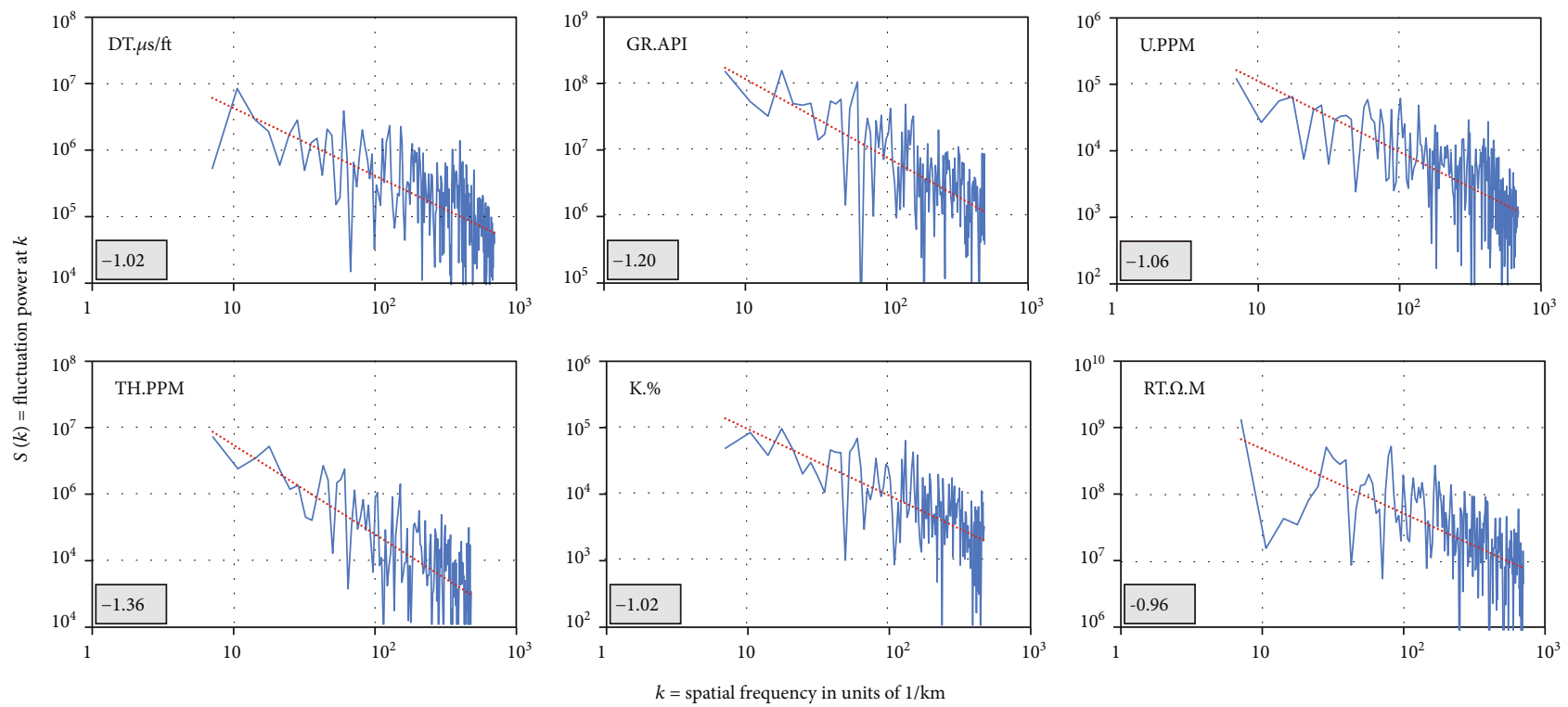

FIGURE 19: Square of the amplitude (fluctuation power of the signal, $S(k)$ ) of Fourier component for different well-log properties plotted against the spatial frequency $(k)$ of the component measured. Data are from the Ahe Formation in well DB-102. The power-scaling exponent is shown in the gray box at the lower left of each plot.

With further deep burial, pressure dissolution between quartz grains occurred and became extensive (Figure 5(h)) and could provide a source of $\mathrm{SiO}_{2}$ for quartz precipitation. Carbonates continued to precipitate. During the deposition of the Kuqa Formation, the late petroleum charge occurred. The fracturing occurred at this period. Late charge mainly occurred in ductile-lean sandstones. Ductile-rich sandstones and tightly calcite-cemented sandstones are poorly charged, although some fractures might help small amounts of hydrocarbons into them (Figure 15).

5.3. Reservoir Quality Forecast for Different Petrofacies. Due to variations in sandstone texture and grain composition, different sandstone petrofacies experienced contrasting diagenetic evolution pathways resulting in great differences in petrophysical properties. By using the method of Cao et al. [46], the porosity evolution models of the three petrofacies has been established (Figure 16).

In the eodiagenetic stage, ductile compaction dominated ductile-rich sandstones and caused extensive loss of intergranular porosity. Calcite cements occupied almost all intergranular pores in tightly calcite-cemented sandstones. Ductile-lean sandstones have a relatively lower degree of compaction relative to ductile-rich sandstones, and strong dissolution occurred in them. When early oil arrived, ductile-rich sandstone and tightly calcite cementedsandstone achieved very low porosities, about $10 \%$ and 5\%, respectively (Figure 16), and they were subsequently not charged by petroleum.

The ductile-lean sandstones remained relatively porous, with a porosity of $18 \%$ (Figure 16), and were significantly charged by early oils. With further burial, the porosity of ductile-lean sandstone was further reduced by cementation of quartz, carbonates, and clay minerals. When the late hydrocarbon charge occurred, ductile-lean sandstones still had moderate porosity, about $12 \%$, and were preferentially charged with petroleum. Ductile-lean sandstones constitute effective reservoir rock in deep reservoirs.

In this study, the classification of sandstone petrofacies has been based on texture and compositions of sandstones, diagenesis type and process, and pore types. The classification of petrofacies by this method is consistent with well $\log$ responses. Well $\log$ responses can be used to identify and forecast petrofacies variations in wells that lack cores. DT value is plotted against GR and RD value (Figure 17). Ductile-lean sandstones contain less abundant clay-rich lithic fragments and muddy matrix and have relatively lower GR values compared to ductile-rich sandstones. Their DT readings are higher due to abundant pores in them. Ductile-rich sandstones and tightly calcite-cemented sandstones have low DT values, but the GR values of ductilerich sandstones are significantly higher than tightly calcitecemented sandstones. In a typical vertical well profile, the reservoirs are more heterogeneous, and different petrofacies show an alternating spatial distribution (Figure 18).

The concept of petrofacies can be used to recognize the main controlling factors affecting the petrophysical properties of sandstones $[47,48]$. The well-log responses of the sandstone petrofacies can be used to calibrate seismic signatures to obtain a consistent understanding of the subsurface reservoirs. This is of great significance to quantitatively evaluate the heterogeneity of deep reservoirs and to forecast reservoir quality of deep reservoirs.

5.4. Spatial Correlation of Fluid Flow. Fluid-rock interactions are spatially correlated at all scale lengths $[49,50]$. Figure 19 shows well-log property sequence spectra scale $S(k)$ as a power law in spatial frequency $k, S(k) \propto 1 / k^{\beta}, \beta \approx 1$. The scaling exponent ranges from 0.96 to 1.36 , with mean value $\beta$ $\approx 1.0 \pm 0.15$, highly consistent with the study from Leary 


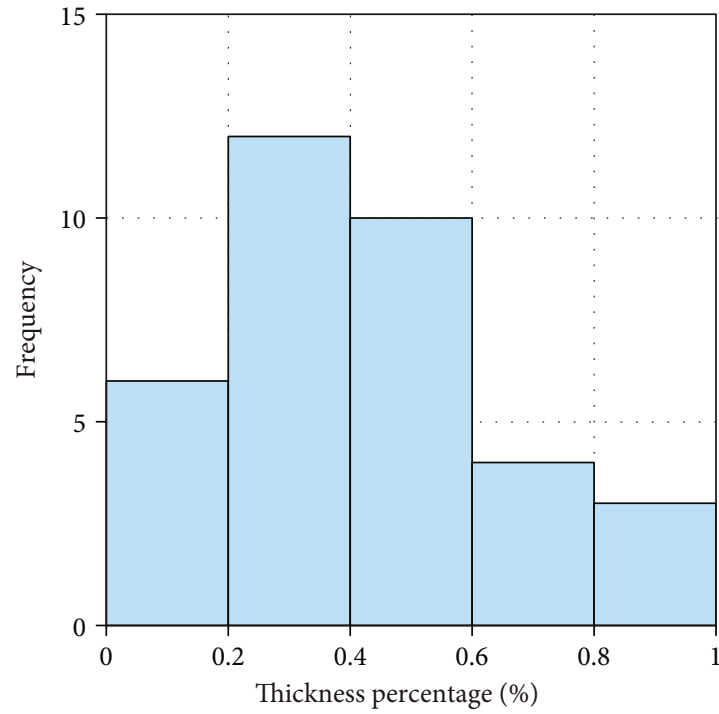

(a)

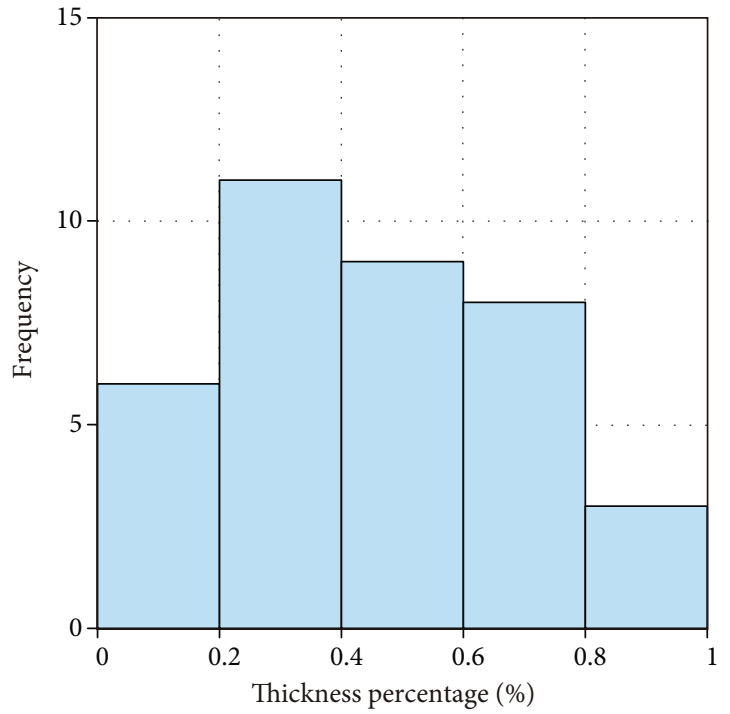

(b)

FIgURE 20: Frequency histograms of thickness percentage of ductile-lean sandstone (a) and ductile-rich sandstone (b). The thickness percentage is calculated in units of $1 / 5 \mathrm{~m}$ between $4965 \mathrm{~m}$ and $5140 \mathrm{~m}$ in well DB-102 in Figure 18.

et al. [49]. Gamma logs can track the distribution of radionuclide elements $\mathrm{U}, \mathrm{Th}$, and $\mathrm{K}$ in soluble minerals and thus indicate where and how fluids flow. The gamma ray activity from solute minerals dispersed through fluid flow displays a pink noise, scale invariant, $1 / k$ power distribution.

As expected from Figures 10(b), 10(d), and 11(a), the systematical spatial correlations between porosity $\varphi$ and $\log$ arithm of permeability $\log (\kappa)$ indicate that the poroperm fluctuations are spatially organized in roughly the same way. This expresses the empirical spatial fluctuation relation $\delta \varphi \propto \delta \log (\kappa)$. Furthermore, it is seen that how a normal distribution of porosity results in the lognormal distribution of permeability, shown in Figures 10(a) and 10(c), if it is recognized that permeability requires a connection condition to be met. Well productivity is lognormality distributed due to spatially correlated porosity, $\kappa \propto \exp (\alpha \varphi)$. The different sandstone petrofacies have a different range of porosity and permeability (Figure 10(c)), but pores and pore connections in each petrofacies fundamentally control permeability in the form. Additionally, the vertical sequences of the interpreted sandstone petrofacies, ductile-lean sandstone and ductile-rich sandstone, are normally distributed (Figure 20). The distribution of tightly calcite-cemented sandstones is highly rare and is not calculated. This normal distribution can be well interpreted by the empirics that crustal flow spatial variations are systematically correlated from $\mathrm{mm}$ to $\mathrm{km}$. Translating the flow spatial correlation feature into numerical form is helpful for fluid flow simulation [49].

\section{Conclusions}

(1) The Ahe Formation sandstones in the eastern Kuqa Depression are fine- to coarse-grained sandstones. The sandstones consist of litharenites and minor feldspathic litharenites. Low-grade metamorphic rock fragments are the most important component of rock fragments

(2) Based on detrital components and texture of sandstones, diagenetic types and degree, and pore types, three petrofacies were defined: ductile-rich sandstone, ductile-lean sandstone, and tightly calcitecemented sandstone. Ductile-lean sandstones are mainly medium- to coarse-grained varieties with less detrital matrix and have relatively low degree of compaction, low total content of cements, and strong dissolution of framework grains. The petrofacies contain primary intergranular pores, intragranular dissolution pores, and microfractures and have good petrophysical properties. On contrary, ductile-rich sandstones are matrix-rich, fine- to mediumgrained sandstones, and show strong compaction. They have relatively poorer reservoir quality. Tightly calcite-cemented sandstones are mainly medium- to coarse-grained sandstones with a lower degree of compaction. This petrofacies also has relatively quality

(3) In the eodiagenetic stage, intergranular porosity was extensively reduced in ductile-rich sandstones and tightly calcite-cemented sandstones due to strong ductile compaction and complete calcite cementation. Before the early oil charge (25-12 Ma), the two petrofacies had evolved into tight rocks and were hardly charged by early oils. On contrary, the degree of compaction in ductile-lean sandstones in the eodiagenetic stage was relatively low and grain dissolution was extensive. When the early oil arrived, ductile-lean sandstones remained relatively porous and were significantly charged by early oils. With continued burial, the porosity of ductile-lean 
sandstones was further deteriorated due to the cementation of quartz, carbonate, and clay minerals. When the late hydrocarbon charge occurred (5$0 \mathrm{Ma})$, ductile-lean sandstones still had a moderate porosity condition and were preferentially charged by petroleum. Ductile-lean sandstones formed effective reservoir rocks in deep reservoirs

(4) By translating petrofacies to well-log signatures, different sandstone petrofacies can be recognized in wells that lack cores. The vertical sequences of the interpreted sandstone petrofacies have a normal distribution. It is possible to forecast spatial correlation of fluid flow variations by observations of empirical well-core and well-log properties

\section{Appendix}

\section{A.1. Samples and Methods}

A.1.1. Porosity and Permeability Measurement. The porosity and permeability were measured using an ULTRAPORE200A helium porosimeter and an ULTRA-PERMTM200 permeameter at room temperature and atmospheric pressure $\left(23^{\circ} \mathrm{C}, 0.1 \mathrm{MPa}\right)$ and $50 \%$ humidity.

A.1.2. Thin Section Petrology. To determine petrology of sandstones, 32 samples were selected from conventional core to represent various lithofacies and oil shows. All samples were impregnated with blue epoxy resin prior to preparing thin section to indicate porosity. Half of each thin section was stained with Alizarin Red S and K-ferricyanide for distinguishing different carbonate minerals. Sandstone petrography, including framework grains, detrital matrix, authigenic minerals, and grain size, roundness and sorting, and porosity, was determined by the 300-pointed modal analysis using a ZEISS Scope. A1 microscope.

A.1.3. $X$-Ray Diffraction (XRD). The $<2 \mu \mathrm{m}$ fraction was separated from the sandstone to examine clay species using a $\mathrm{D} / \mathrm{max}-2500 \mathrm{X}$-ray diffractometer (Cu Ka radiation, $40 \mathrm{kV}$, $40 \mathrm{~mA})$.

\section{A.1.4. Scanning Electron Microscope (SEM) and Backscatter} Electron (BSE). To furthermore identify diagenetic minerals, textural relationships between different minerals, and rock pore structure characteristics, ten samples were selected for scanning electron microscope (SEM) observations. A Nova NanoSEM 450 high resolution field emission SEM equipped with Oxford Aztec energy spectrometer (EDS) and backscatter electron (BSE) detector was used in this study. These samples are gold-coated and fixed on a carbon disk. All images were taken at $20 \mathrm{keV}$ with 5-8 $\mathrm{mm}$ working distance.

A.1.5. Fluid Inclusion Analysis. Eighteen samples were collected to prepare $100 \mu \mathrm{m}$ thick, doubly polished sections for petrographic observation and microthermometric measurement of fluid inclusions. Fluid inclusions were examined using a Nikon 80I microscope under both transmitted and ultraviolet (UV) lights. The wavelength of the emission fluorescence is greater than $420 \mathrm{~nm}$. Homogenization tempera- ture measurement of fluid inclusions was carried out using a calibrated Linkam THMSG600 heating-freezing stage. The precision is $\pm 0.1^{\circ} \mathrm{C}$. The fluid inclusions showing textural or microthermometric evidence for stretching, necking down, leakage, or decrepitation were excluded from this study.

\section{Data Availability}

Thin section petrography, SEM, and fluid inclusion data used to support the findings of this study are available from the corresponding author upon request.

\section{Conflicts of Interest}

The authors declare that they have no competing interests.

\section{Acknowledgments}

This study has been funded by the Strategic Priority Research Program of the Chinese Academy of Sciences (no. XDA14010202) and the National Science and Technology Major Project (no. 2017ZX05008-004). This study has been also financially supported by the National Natural Science Foundation of China (nos. 41902135, 42030808, and 41372151). The authors thank Dr. Jiangjie Zhang for his help concerning Fourier analysis of well-log data.

\section{References}

[1] L. D. Sun, C. N. Zou, R. K. Zhu et al., "Formation, distribution and potential of deep hydrocarbon resources in China," Petrolum Exploration and Development, vol. 40, no. 6, pp. 641-647, 2013.

[2] S. N. Ehrenberg and P. H. Nadeau, "Sandstone vs. carbonate petroleum reservoirs: a global perspective on porosity-depth and porosity-permeability relationships," AAPG Bulletin, vol. 89, no. 4, pp. 435-445, 2005.

[3] X. Q. Pang, C. Z. Jia, and W. Y. Wang, "Petroleum geology features and research developments of hydrocarbon accumulation in deep petroliferous basins," Petroleum Science, vol. 12, no. 1, pp. 1-53, 2015.

[4] J. W. Schmoker, "Resource-assessment perspectives for unconventional gas systems," AAPG Bulletin, vol. 86, no. 11, pp. 1993-1999, 2002.

[5] L. D. Meckel and M. R. Thomasson, "Pervasive tight-gas sandstone reservoirs: an overview," in Understanding, Exploring, and Developing Tight-Gas Sands-2005 Vail Hedberg Conference, S. P. Cumella, K. W. Shanley, and W. K. Camp, Eds., vol. 3 of AAPG Hedberg Series, pp. 13-27, Tulsa, OK, USA, 2008.

[6] X. Y. Cai, "Gas accumulation patterns and key exploration techniques of deep gas reservoirs in tight sandstone: an example from gas exploration in the Xujiahe Formation of the western Sichuan Depression, the Sichuan Basin," Oil \& Gas Geology, vol. 31, no. 6, pp. 707-714, 2010.

[7] X. R. Luo, L. K. Zhang, Y. H. Lei, and W. Yang, "Petroleum migration and accumulation: modeling and applications," AAPG Bulletin, vol. 104, no. 11, pp. 2247-2265, 2020.

[8] X. R. Luo, L. Q. Zhang, L. K. Zhang et al., "Heterogeneity of clastic carrier bed and hydrocarbon migration and accumulation," Acta Petrolei Sinica, vol. 41, no. 3, pp. 253-272, 2020. 
[9] S. Morad, J. M. Ketzer, and L. F. De Ros, "Spatial and temporal distribution of diagenetic alterations in siliciclastic rocks: implications for mass transfer in sedimentary basins," Sedimentary, vol. 47, pp. 95-120, 2000.

[10] S. Morad, K. al-Ramadan, J. M. Ketzer, and L. F. de Ros, “The impact of diagenesis on the heterogeneity of sandstone reservoirs: a review of the role of depositional facies and sequence stratigraphy," AAPG Bulletin, vol. 94, no. 8, pp. 1267-1309, 2010.

[11] J. M. Ajdukiewicz and R. H. Lander, "Sandstone reservoir quality prediction: the state of the art," AAPG Bulletin, vol. 94, no. 8, pp. 1083-1091, 2010.

[12] B. F. Cao, X. R. Luo, L. K. Zhang, F. Sui, H. Lin, and Y. Lei, "Diagenetic evolution of deep sandstones and multiple-stage oil entrapment: a case study from the lower Jurassic Sangonghe Formation in the Fukang Sag, central Junggar Basin (NW China)," Journal of Petroleum Science and Engineering, vol. 152, pp. 136-155, 2017.

[13] X. R. Luo, C. Z. Hu, Z. Y. Xiao et al., "Effects of carrier bed heterogeneity on hydrocarbon migration," Marine and Petroleum Geology, vol. 68, pp. 120-131, 2015.

[14] C. Z. Jia, J. Y. Gu, and G. Y. Zhang, "Geological conditions of formation of large and medium-sized gas fields in Kuqa depression," Chinese Science Bulletin, vol. 47, pp. 49-55, 2002.

[15] D. Jia, H. F. Lu, and D. S. Cai, "Structural analyses of Kuqa foreland fold - thrust belt along the northern margin of tarim basin," Geotectonica et Metallogenia, vol. 21, no. 1, pp. 1-8, 1997.

[16] D. F. He, X. Y. Zhou, H. J. Yang, G. L. Lei, and Y. J. Ma, "Geological structural and its controls on giant oil and gas fields in Kuqa depression, Tarim Basin," Geotectonica et Metallogenia, vol. 33, no. 1, pp. 19-32, 2009.

[17] C. Z. Jia, G. Q. Wei, B. L. Li, A. C. Xiao, and Q. G. Ran, “Tectonic evolution of two-epoch foreland basins and its control for natural gas accumulation in China's mid-western area," Acta Petrolei Sinica, vol. 24, no. 2, pp. 13-17, 2003.

[18] C. D. Wu, C. S. Lin, Y. P. Shen et al., "Sequence stratigraphy and depositional environments of the Kuche depression," Acta Sedimentologica Sinica, vol. 20, no. 3, pp. 400-407, 2002.

[19] H. X. Liu, T. X. Qin, and Z. Y. Yang, "Sedimentary facies of the Triassic-Jurassic strata in the Tarim Basin, Xinjiang," Sedimentary Geology and Tethyan Geology, vol. 23, no. 1, pp. 37-44, 2003.

[20] K. N. Huang, J. Z. Zhan, Y. S. Zhou, Z. Wang, C. M. Zhou, and J. N. Xiao, "Sedimentary environments and palaeoclimate of the Triassic and Jurassic in Kuqa river area, Xinjiang," Journal of Palaeogeography, vol. 5, no. 2, pp. 197-208, 2003.

[21] C. D. Wu, Q. Q. Wang, X. Feng, and X. Gu, "Multi-grain fraction analysis of clay minerals and the geolgical meanings of sedimentary envirionment and diagenesis in Jurassic of Kuqa Depression, Xinjiang, China," Acta Petrologica Sinica, vol. 23, no. 7, pp. 165-1663, 2007.

[22] H. He, J. H. Guo, and Y. F. Gao, "Jurassic sequence stratigraphy and sedimentary facies in Kuqa depression of Tarim Basin," Journal of Jianghan Petroleum Institute, vol. 24, no. 4, pp. 1-3, 2002.

[23] H. L. Zhang, J. F. Shou, and Z. L. Chen, "Sedimentary characteristics and sandstone body distribution of the lower Jurassic in Kuqa depression," Journal of Palaeogeography, vol. 4, no. 3 , pp. 47-58, 2002.
[24] Y. Ju, X. W. Sun, L. W. Liu, Y. N. Xie, and H. X. Wei, "Characteristics of Jurassic tight sandstone gas reservoir in Dibei area of Kuqa depression, Tarim Basin," Xinjiang Petroleum Geology, vol. 35, no. 3, pp. 264-267, 2014.

[25] B. Lu, The characteristics of hydrocarbon accumulation and the favorable exploration zone in eastern Kuqa depression, University of Chinese Academy of Science (Institute of Porous Flow and Fluid Mechanics), 2015.

[26] B. M. Zhang, M. J. Zhao, Z. Y. Xiao et al., "Characteristic of premium gas source rocks in Tarim Basin," Xinjiang Petroleum Geology, vol. 21, no. 1, pp. 33-37, 2000.

[27] R. L. Folk, Petrology of Sedimentary Rocks, Hemphills, Austin, Texas, USA, 1974.

[28] D. Emery and A. Robinson, Inorganic Geochemistry: Applications to Petroleum Geology, John Wiley \& Sons, 1993.

[29] C. D. McAuliffe, "Oil and gas migration-chemical and physical constraints," AAPG Bulletin, vol. 63, no. 5, pp. 761-781, 1979.

[30] F. Li, Z. X. Jiang, Z. Li, J. L. Liu, Y. Wang, and X. Luo, "Fluid inclusion characteristics and hydrocarbon charge history of Dibei gas reservoir in the Kuqa depression," Journal of Central South University (Science and Technology), vol. 47, no. 2, pp. 515-523, 2016.

[31] F. Li, Z. X. Jiang, Z. Li et al., "Palaeo-fluid evidence for the twostage hydrocarbon charges in Dibei gas reservoir of Kuqa depression," Natural Gas Geoscience, vol. 25, no. 7, pp. 10331041, 2014.

[32] H. Shi, X. R. Luo, G. L. Lei, L. Q. Zhang, L. K. Zhang, and Y. H. Lei, "Diagenesis and fluid flow variability of structural heterogeneity units in tight sandstone carrier beds of Dibei, eastern Kuqa Depression," Geofluids, vol. 2017, 15 pages, 2017.

[33] S. Henares, L. Caracciolo, C. Viseras, J. Juan Fernández, and L. M. Yeste, "Diagenetic constraints on heterogeneous reservoir quality assessment: a Triassic outcrop analog of meandering fluvial reservoirs," AAPG Bulletin, vol. 100, no. 9, pp. 1377-1398, 2016.

[34] D. A. C. Manning, "Acetate and propionate in landfill leachates: implications for the recognition of microbiological influences on the composition of waters in sedimentary systems," Geology, vol. 25, no. 3, pp. 279-281, 1997.

[35] Y. H. Shuai, S. C. Zhang, Y. Gao et al., "Effect and quantitative evaluation of $\mathrm{CO}_{2}$ derived from organic matter in coal on the formation of tight sandstone reservoirs," Science China-earth Sciences, vol. 56, no. 5, pp. 756-762, 2013.

[36] M. A. S. Moraes and L. F. De Ros, "Infiltrated clays in fluvial Jurassic sandstones of Reconcavo Basin, Northeastern Brazil," Journal of Sedimentary Research, vol. 60, no. 6, pp. 809-819, 1990.

[37] C. Rossi, O. Kälin, J. Arribas, and A. Tortosa, "Diagenesis, provenance and reservoir quality of Triassic TAGI sandstones from Ourhoud field, Berkine (Ghadames) Basin, Algeria," Marine and Petroleum Geology, vol. 19, no. 2, pp. 117-142, 2002.

[38] R. C. Surdam, L. J. Crossey, E. S. Hagen, and H. P. Heasler, "Organic-inorganic interactions and sandstone diagenesis," AAPG Bulletin, vol. 73, no. 1, pp. 1-23, 1989.

[39] J. S. Seewald, "Organic-inorganic interactions in petroleumproducing sedimentary basins,” Nature, vol. 426, no. 6964, pp. 327-333, 2003.

[40] G. Yuan, Y. Cao, H.-M. Schulz et al., "A review of feldspar alteration and its geological significance in sedimentary basins: 
from shallow aquifers to deep hydrocarbon reservoirs," EarthScience Reviews, vol. 191, pp. 114-140, 2019.

[41] K. Bjorlykke and P. K. Egeberg, "Quartz cementation in sedimentary basins," AAPG Bulletin, vol. 77, no. 9, pp. 15381548, 1993.

[42] C. Peltonen, Ø. Marcussen, K. Bjørlykke, and J. Jahren, "Clay mineral diagenesis and quartz cementation in mudstones: the effects of smectite to illite reaction on rock properties," Marine and Petroleum Geology, vol. 26, no. 6, pp. 887-898, 2009.

[43] L. Q. Zhang, Y. M. Yan, X. R. Luo, Z. B. Wang, and H. Z. Zhang, "Diagenetic differences of tight sandstone of the Lower Jurassic Ahe Formation in the Yiqikelike area of Kuqa depression, Tarim Basin," Earth Science Frontiers, vol. 25, no. 2, pp. 170-178, 2018.

[44] L. M. Ni and Z. Li, "Study on rock heterogeneity caused by sandstone reservoir structure in Arhe Formation of Yinan anticline in Kuqa Depression," Journal of Jilin University (Earth Science Edition), vol. AI, pp. 1045-1046, 2015.

[45] S. Morad, "Carbonate cementation in sandstones: distribution patterns and geochemical evolution," in Carbonate Cementation in Sandstones, S. Morad, Ed., vol. 26 of Special Publication, pp. 1-26, The International Association of Sedimentologists, Blackwell Science, 1998.

[46] B. F. Cao, Availability of Tight Gas Sand Reservoir and Formation: A Case Study from Upper Paleozoic Shanxi Formation, University of Chinese Academy of Science (Institute of Geology and Geophysics), Southeatern Ordos Basin, 2017.

[47] L. F. De Ros and K. Goldberg, "Reservoir Petrofacies: A Tool for Quality Characterization and Prediction," in $A A P G$ Annual Convention and Exhibition, Long Beach, CA, USA, 2007.

[48] B. F. Cao, X. R. Luo, L. K. Zhang, Y. H. Lei, and J. S. Zhou, "Petrofacies prediction and 3-D geological model in tight gas sandstone reservoirs by integration of well logs and geostatistical modeling," Marine and Petroleum geology, vol. 114, p. 104202, 2020.

[49] P. Leary, P. Malin, and R. Niemi, "Fluid flow and heat transport computation for power-law scaling poroperm media," Geofluids, vol. 2017, Article ID 9687325, 2017.

[50] P. E. Malin, P. C. Leary, L. M. Cathles, and C. C. Barton, "Observational and critical state physics descriptions of longrange flow structures," Geosciences, vol. 10, no. 2, p. 50, 2020. 